\title{
Globalization and Inflation: Structural Evidence from a Time Varying VAR Approach
}

Francesco Bianchi

Duke University University of Pennsylvania
Andrea Civelli

University of Arkansas

July 2013

ERID Working Paper Number 157

This paper can be downloaded without charge from the Social Science Research Network Electronic Paper Collection: http://ssrn.com/abstract=2331600

\section{Economic Research Initiatives at Duke WORKING PAPERS SERIES

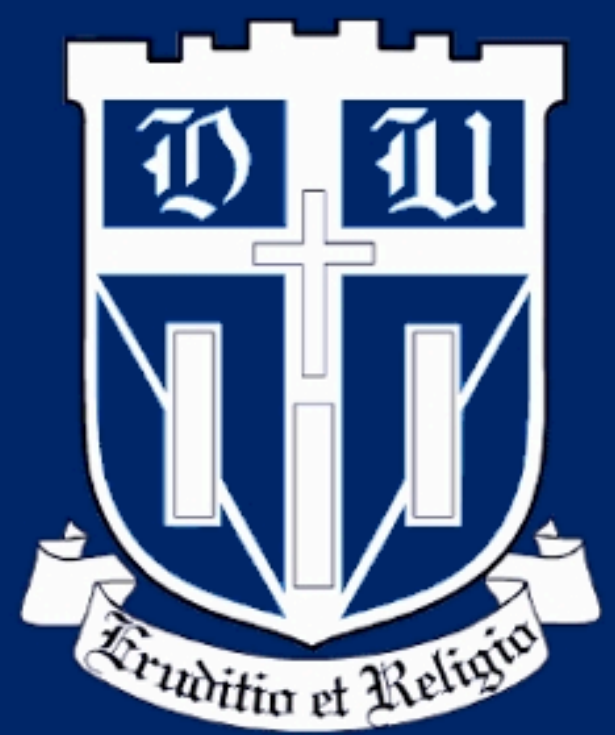




\title{
Globalization and Inflation: Structural Evidence from a Time Varying VAR Approach*
}

\author{
Francesco Bianchi \\ Andrea Civelli \\ Duke University \\ University of Arkansas
}

\begin{abstract}
Under the Globalization Hypothesis for inflation, as globalization increases, global economic slack should progressively replace the domestic gap in driving inflation. In order to assess the empirical support for this theoretical prediction, we use impulse response functions of inflation to domestic and foreign output gap shocks from a TV-VAR model estimated for eighteen countries. The main results of the analysis are twofold: First, the structural results show that global slack affects the dynamics of inflation in many countries, yet these effects do not get stronger over time. Second, a panel analysis that exploits the cross-section characteristics of the response functions shows that globalization, measured in terms of openness and business cycles integration, is positively related to the effects of global slack on inflation. The degree of openness of a country and its economic integration into the global economy are complementary rather than overlaid forces.
\end{abstract}

JEL Classification: E31, F02, F41

Keywords: Globalization, Inflation, Time-variation, VAR

\section{Introduction}

The Globalization Hypothesis (GH) argues that the internationalization of goods and financial markets has to increase the dependence of national macroeconomic outcomes, such as inflation rates and business cycles, on international factors. Global determinants would eventually replace the more traditional domestic factors.

The versatility of the GH idea, however, calls for some caution in its application. For instance, the well-documented reduction in volatility and levels of domestic inflation rates across the world is explained by

\footnotetext{
${ }^{*}$ We thank Alan Blinder, Christopher Sims, Mark Watson, John Seater, Sandra Eickmeier and participants at Princeton University seminar and the "Inflation Dynamics in a Post-Crisis Globalized Economy" 2013 conference for very useful comments and discussions. Francesco Bianchi, Department of Economics, Duke University, 213 Social Sciences Building, Box 90097, Durham, NC 27708. Email: francesco.bianchi@duke.edu. Andrea Civelli, Department of Economics, University of Arkansas, Business Building 402, Fayetteville, AR 72701. Email: andrea.civelli@gmail.com.
} 
a common global factor which, as predicted by the GH, can be related to the increase in global openness. ${ }^{1}$ Figure 1 illustrates the dynamics of national inflations for the set of countries included in our study. The moderation of inflation comes along with a rise in openness for many countries as shown in Figure 2, in which the ratio of the sum of imports and exports to GDP is plotted for ten countries including, among the others, U.S., Japan, Germany, U.K., and China. In these economies, the ratio has increased on average by 5 to 10 percentage points since the 70's. The tighter comovements of national inflation rates across countries and the evidence of higher integration occurring in the goods markets led some authors to extend, in a presumably natural way, the GH to two other aspects of the national inflation dynamics. The first aspect is the Phillips Curve relation, which in a closed economy is traditionally used to link short run movements of inflation to the domestic output gap. The main implication of the GH in this respect is that global economic slack should progressively replace domestic output gap in driving national inflation rates. The second is the so-called China effect; the view that lower import prices from emerging economies may have reduced prices in the industrialized countries. Surprisingly, although one would consider these two applications of the GH intuitively sound, neither of them finds an unambiguous confirmation on the empirical ground. ${ }^{2}$

In this paper, we focus on the implications of the GH for the Phillips Curve. The analysis tackles two main questions. First of all, it is important to understand whether globalization matters for the dynamics of domestic inflation at all. This point is important empirically, from a monetary policy perspective ${ }^{3}$ and theoretically, since the New Keynesian open economy literature explicitly recognizes a primary role to foreign forces in the determination of the domestic macroeconomic dynamics. We demonstrate this role is deeper, in the sense of being more structural, than what the analysis based only on univariate estimates of the Phillips Curve has revealed so far. Once the importance of these global effects for inflation is assessed, the second interesting point is to verify whether the impact of the foreign output gap on domestic inflation rates has changed over time in a way consistent with the GH as defined in Claudio Borio and Andrew Filardo (2007).

In answering these questions we provide three key methodological contributions. The first one is the construction of a dataset, comparable to the one used by Jane Ihrig, Steven B. Kamin, Deborah Lindner, and Jaime Marquez (2010), which allows us to have a homogenous definition of the foreign gap and the

\footnotetext{
${ }^{1}$ See, for example, Matteo Ciccarelli and Benoit Mojon (2010), Sandra Eickmeier and Katharina Pijnenburg (2013), and Haroon Mumtaz and Paolo Surico (2008).

${ }^{2}$ Numerous empirical papers have studied the relevance of the China effect. Among them, Natalie Chen, Jean M. Imbs, and Andrew Scott (2009) use disaggregated data for the EU to show that openness lowers prices by both reducing markups and raising productivity. Eduard N. Gamber and Juann H. Hung (2001) report that some U.S. sectorial prices are sensitive to prices of imports in the same sector. On the other hand, Steven B. Kamin, Mario Marazzi, and John W. Schindler (2006) find a small impact of Chinese exports on global import prices and CPI inflation. More recently, Raphael Auer and Andreas M. Fisher (2010) and (2012) propose an improved estimation methodology and find that import competition from low-wage countries has strong downward effects on sectorial prices and equilibrium inflation in the U.S. and Europe. The literature on the relationship between Phillips Curve and globalization is reviewed below.

${ }^{3}$ The interest of policy makers in this issue is attested, for instance, by public speeches by Ben Bernanke (2007) and Richard W. Fisher (2006).
} 
real exchange rate across countries for a very large set of nations. Those measures are constructed using a set of trade-based weights computed adopting the methodology presented by Mico Loretan (2006), and in particular our weights take into account the changes in the trade relations among about 50 countries over the sample 1970 to 2006.

As a second contribution, we employ a time varying coefficients VARs with stochastic volatilities (Timothy Cogley and Thomas J. Sargent (2006) and Giorgio Primiceri (2005)) instead of univariate regressions and subsample analysis. For each country, we can supplement the estimates of the coefficients of the reducedform Phillips Curve with the structural evidence from the impulse response functions of inflation to shocks to the domestic and foreign output gaps. The time varying nature of our estimates allows us to compute the impulse response functions at different points in time and to check whether their shape and significance have changed over the sample.

Finally, we exploit the cross-section dimension of the dataset and of the structural results in a panel analysis to formally quantify the effects of globalization, defined in terms of openness and economic integration of a country, on the relation between domestic inflation and foreign output gap. A particularly sensitive point of our analysis is the relatively moderate increase in openness observed for many countries. This problem makes univariate analysis an unsatisfactory tool to assess the effects of openness on inflation. The large pool of countries we study allows us to cope with this issue through the comparison of economies with very different degrees of openness and integration instead of relying only on the change in openness for an individual country.

In what follows we describe the main results of the paper. We first estimate the reduced form VARs and obtain a set of results directly comparable to the results obtained by previous contributions that make use of univariate regressions and subsample analysis. When analyzing the evolution of the time-varying coefficients, we do not find significant changes, which is contrary to what we would expect based on the GH. However, the structural estimates and the impulse response analysis introduce several new elements which depict a quite different picture with respect to the empirical evidence based on univariate regressions. The response functions of inflation to domestic and foreign output gap shocks are consistently positive and significant for many of the countries and periods in our sample, yet these effects do not grow over time. The lack of the expected time evolution of the response functions suggests that the change in the degree of openness occurred in the sample might have not created the premises necessary to induce significant changes in the structural relations of the variables of the model.

The panel analysis allows us to identify two factors that affect the structural role of the foreign output gap shocks in our analysis: the degree of openness of a country and its economic integration into the global economy. Both of these factors are obviously linked to globalization, but we show that they are 
complementary rather than overlaid forces. We find that the effects of the global economic slack on inflation are positively related to the degree of integration, which in our framework is defined by the correlation of domestic and foreign output gaps. The response functions of inflation to the foreign output gap shocks are positively related to the degree of openness too; however, this relation holds only for countries which are also highly integrated into the global economy.

The debate about the effects of globalization on the Phillips Curve is well represented by the two opposing views expressed by Borio and Filardo and Ihrig et al. Borio and Filardo study an open economy version of the domestic Phillips Curve for a large set of countries. They include a measure of the specific foreign gap in the Phillips Curve for each country in their sample and they provide evidence in favor of the GH. They also demonstrate that their results hold for different measures of the foreign output gap. On the other hand, Ihrig et al. study eleven industrial countries and find little support for the GH. Moreover, they argue that Borio and Filardo's positive conclusions crucially depend on the specific reduced form of the regression they adopt in testing the hypothesis and on how they treat inflation expectations.

Compared to the previous literature, our approach presents two advantages. The first is that it avoids those specification issues related to the treatment of the inflation expectations which have negatively affected the results in Borio and Filardo. The structure of the VAR model itself incorporates these expectations. The second advantage is determined by our econometric methodology. The crucial point in the analysis of this problem is to investigate the change of the relations between inflation and other relevant variables in the economy. In this respect, the time varying coefficients VAR is a very suitable and flexible tool, and it is a clear improvement over sub-sample analysis and rolling estimations. Furthermore, letting the model distinguish between changes in the coefficients and changes in the magnitude of the shocks allows us to account not only for the variation in the structure of the model, but also for differences in the impulse response functions due to changes in the volatility of the shocks. Finally, the new evidence from the structural version of the model can be used to achieve a deeper understanding of the role of the foreign gap in the determination of the dynamics of domestic inflation rates.

There is an extensive empirical literature that studies the relationship between globalization and Phillips Curve. Geoffrey M.B. Tootell (1998) provides some earlier evidence against any direct or indirect effect of foreign capacity utilization on U.S. inflation. He also explores an indirect transmission channel and argues that foreign capacity does not affect U.S. import prices. Alessandro Calza (2009) extends Tootell's approach to the euro area and finds weak evidence that global capacity constraints have explanatory or predictive power for the euro area inflation. He considers both a trade-based and a PPP-based definition of foreign output finding the same results in the two cases. On the other hand, Edward N. Gamber and Juann H. Hung (2001) study the GH for U.S. inflation and they find that the interaction between slack foreign economic 
conditions and increased trade openness helped reducing U.S. inflation in the 1990s. Mark A. Wynne and Erasmus K. Kersting (2007) review the results on the effects of different measures of economic openness on trend inflation reporting a negative, although mild, relationship between the two. They also document a positive correlation between the world output gap and the cyclical component of inflation for the U.S. The results reported by all these papers, however, are mostly based on univariate models of the Phillips Curve while, as we said, one of the main goal of our methodology is to improve on this approach. An exhaustive review of the empirical literature on the GH for inflation is provided by Ihrig et al. A broader overview of the changes in inflation developments over the last decades and of the factors that influence the inflation process, which include globalization, can be found in Gabriele Galati and Melick William (2006). Finally, Fabio Milani (2010) estimates a structural model for the G7 economies and concludes that global output affects domestic inflation only indirectly through the aggregate demand of a country and that, therefore, it should not be included in the specification of the Phillips Curve. We also document the importance of these indirect effects in our structural analysis.

Even from the theoretical perspective, there is no full agreement on the impact of greater globalization and of the foreign business cycle on domestic inflation. Kenneth Rogoff (2003) suggests that higher international competition should make the Phillips Curve steeper, but the empirical evidence definitely points in the opposite direction. Laurence M. Ball (2006) notices that, even though firms compete in more integrated markets, the output gap enters the Phillips Curve because it approximates firms' marginal costs. Ball argues that while competition reduces the average markup making the Phillips Curve potentially flatter, the foreign output gap would replace the domestic gap only if marginal costs had started to depend more on the foreign gap instead of the domestic one, but he does not see any reason to support this view. Argia Sbordone (2007) explores the same point in a formal model with Calvo pricing in which the elasticity of demand depends on the variety of traded goods. She concludes that the increase in trade in the U.S. was not large enough to generate a sufficiently large increase in market competition in order to reduce the slope of the inflation-marginal cost relation.

Finally, this paper is also related to a growing literature that models parameter instability to capture changes in the evolution of the macroeconomy. Frank Schorfheide (2005), Alejandro Justiniano and G. Primiceri (2008), Bianchi (2013), Troy Davig and Taeyoung Doh (2008), and Jesus Fernandez-Villaverde and Juan F. Rubio-Ramirez (2008) introduce parameter instability in DSGE models, while Christopher A. Sims and Tao Zha (2006), Primiceri (2005), and Cogley and Sargent (2005) work with structural VARs.

The rest of the paper is organized as follows. Section 2 introduces the implications of the GH and relates it to the theoretical New Keynesian framework currently used in open economy general equilibrium models. Section 3 presents the motivations and goals of our approach and briefly outlines the estimation methodology. 
Section 4 describes the dataset we use (more details will be necessarily left to the Appendix). Sections 5 and 6 present and interpret the results for the eighteen countries in our sample; and the final Section concludes.

\section{The Globalization Hypothesis}

In this section, we discuss both the theoretical and the empirical implications of the Globalization Hypothesis for inflation in the context of the Phillips Curve model.

\subsection{Empirical Considerations}

The Phillips Curve provides a theoretical and empirical relation between a country's inflation and its domestic output gap. The declining slope of the relation, which is typically found using the most recent data, along with the narrowing comovements of inflations across countries and the increasing integration of the global economy over the last decades, have suggested a new role for international forces in driving national inflation outcomes. In particular, the Globalization Hypothesis implies three main predictions with regard to the open economy version of the Phillips Curve in equation (1), where the foreign output gap $y_{t}^{f}$ and the import price inflation $\pi_{t}^{m}$ have been added to the domestic gap $y_{t}^{d}$ and the expected inflation $E_{t} \pi_{t+1}$ in the regression equation of the domestic CPI inflation $\pi_{t} \cdot{ }^{4}$

$$
\pi_{t}=E_{t} \pi_{t+1}+\beta y_{t}^{d}+\delta y_{t}^{f}+\gamma \pi_{t}^{m}
$$

1. The first prediction is that the role played by $y_{t}^{d}$ should get increasingly less important as globalization increases. This implies declining estimates of $\beta$ both in closed and open versions of the Phillips Curve.

2. The second is that $y_{t}^{f}$ should progressively replace $y_{t}^{d}$ as globalization increases, which means $\delta$ must be significantly positive and possibly increasing over time.

3. Finally, the third prediction is that $\gamma$ should increase, since the responsiveness of $\pi_{t}$ to import prices should be greater when globalization is more intense.

These predictions of the GH sound very intuitive and appealing; however, there is no clear empirical evidence supporting this theory. ${ }^{5}$ Since empirical results are usually based on univariate estimates of equation (1), conflicting conclusions can be determined by the specific regression used to test the hypothesis.

\footnotetext{
${ }^{4}$ The specification of the term $\pi_{t}^{m}$ varies among authors. In some cases, it is the inflation of import prices or the unit labor cost, as in Borio and Filardo, while in other cases it is taken in deviation from the home country inflation as in Ihrig et al.

${ }^{5}$ This is not necessarily in contradiction with the presence of global dynamics since global factors can be attributed to a stronger international coordination of monetary policy practices or to tighter international linkages, which do not necessarily have to go through the impact of foreign slackness on domestic inflation.
} 
Furthermore, Ihrig at al. (IEA henceforth) show also that the results can depend on the adopted definition of the foreign output gap, which introduces a delicate issue about the construction of homogenous measures of foreign output gap across countries.

One of the key aspects of equation (1) is the expectation term $E_{t} \pi_{t+1}$. Studies that find positive and increasing $\delta$ along with decreasing $\beta$ use the HP-filtered inflation series as a proxy for the underlying trend CPI inflation; this is the approach followed by Borio and Filardo (BF henceforth) for instance. This choice for the expectations leaves enough variability in the dependent variable to detect the relative contribution of domestic and foreign gaps to the persistence of inflation, but it causes the residuals of the regression to be autocorrelated. Even though autocorrelated residuals do not bias the estimates of the coefficients of a regression, this is commonly taken as an indication of mispecification of the equation. A correct specification is recovered dropping the filtered series and including some lagged values of $\pi$ in the regression instead, as shown by IEA. Under this specification, the statistical significance of $\delta$ vanishes almost completely, even though also the significance of $\beta$ is critically reduced for many countries. ${ }^{6}$

A second result typically found in literature is that the effects of import prices on domestic inflation are weak. The estimated $\gamma$ is generally only marginally significant and extremely small compared to $\delta$ and $\beta$; it does not increase over time and it is not particularly related to changes in trade openness. BF report similar conclusions for other international prices which might be relevant in explaining domestic inflation, such as the price of oil and a measure of the global unit labor cost.

Finally, the definition and measurement of globalization is an important issue too. Globalization is commonly defined as the degree of international integration of national markets. This is a quite complex phenomenon that can be measured over several dimensions such as real markets' coordination, financial markets' integration, trade or labor markets' openness. In this paper, we measure globalization in terms of business cycles coordination and trade openness. Given the dataset described below, business cycles coordination is simply defined as the correlation between domestic and foreign output gaps while a trade openness index is constructed as the ratio to GDP of the sum of imports and exports. The choice of these measures is justified by three reasons. First, the scope of the paper is to study the relation between inflation and output gaps, so the use of real markets and business cycles integration is relevant. Second, previous empirical literature has already looked at trade openness as an indicator of globalization without finding strong links to the Globalization Hypothesis for inflation. Third, in the theoretical models of the openeconomy Phillips Curve openness boosts the importance of the foreign output gap on domestic inflation.

\footnotetext{
${ }^{6}$ Calza estimates a forward looking Phillips Curve of the type in (1) for the euro area incorporating a more formal and satisfactory modeling of inflation expectations than BF. He shows that his better treatment of expectations makes the coefficient of the foreign output gap negative and not statistically significant while increasing the significance of the coefficient of the domestic gap.
} 
The next section elaborates more on this last point. ${ }^{7}$

\subsection{Theoretical Considerations}

The New Keynesian Phillips Curve is a well known result of modern general equilibrium models. It is a forward looking equation that relates CPI inflation to the marginal costs of optimizing firms that set prices according to a Calvo price setting scheme. The labor supply optimal condition of the consumer and the production function then allow one to express the marginal cost in function of the output gap and to derive the standard representation of the Phillips Curve.

The same modeling device has been applied to open economy models too. If firms can export their goods to a foreign country and are allowed to price discriminate between home and foreign markets, the cross border pricing decision introduces a dependence of the inflation of a country on the marginal cost of the exporting firms in the other country and, therefore, on the foreign country output gap. Richard Clarida, Jordi Gali, and Mark Gertler (2002) and Giancarlo Corsetti and Paolo Pesenti (2005) introduced this model for the analysis of international monetary policy; Jordi Gali and Tommaso Monacelli (2008) and Monacelli (2005) refined it for the small open economy case; soon thereafter it became the workhorse model in the open economy DSGE literature.

This natural extension of the closed economy framework provides the theoretical background at the base of the Globalization Hypothesis. The specific form taken by the open economy New Keynesian Phillips Curve varies according to the details of each model. However, with local currency pricing, home bias in consumption and perfect risk sharing, it would usually read

$$
\pi_{t}=\mu E_{t} \pi_{t+1}+\nu\left[(1-h) y_{t}^{d}+h y_{t}^{f}\right]+\Gamma_{t}
$$

In what follows, we will point out a few characteristics of equation (2). For a rigorous micro foundation of this equation the reader should refer to Jón Steinsson (2008) for heterogenous labor markets and should refer to Nicola Zaniboni (2008) for the difference between local currency and producer currency pricing. ${ }^{8}$ CPI inflation $\pi_{t}$ presents a forward looking term multiplied by $\mu$, the discount factor in the utility function of the consumer. Inflation also depends on the weighted average of the domestic and foreign output gap. The weight $(1-h)$ is the consumption home bias coefficient while $\nu$ summarizes the responsiveness of inflation

\footnotetext{
${ }^{7} \mathrm{~A}$ comparison on the effects of different types of economic openness on trend inflation is provided by Wynne and Kersting. They compare three different measure of openness (openness in trade, in capital markets, and in labor markets) and they report very similar results for all of them.

${ }^{8}$ An earlier example of open economy New Keynesian Phillips Curve is also derived by Assaf Razin and Chi-Wa Yuen (2002) under the assumption that prices are set one period in advance and under complete capital and goods mobility. Their model demonstrates that the slope of the Phillips Curve must be flatter in open economy than in closed economy.
} 
to the output gap. ${ }^{9}$ The last term $\Gamma_{t}$ accounts for the impact on inflation of some measure of international competitiveness. This measure is model specific, but it can usually include the term of trade, the deviation from the law of one price of import prices, the deviations from purchasing power parity of the real exchange rate. Equation (1) adopted in the previous section is an example of empirical specification derived from (2).

It is evident from (2) that the foreign output gap should enter the Phillips Curve equation in a direct way and its coefficient should be smaller relative to that of the domestic output gap if there is home bias in consumption. The empirical studies based on univariate regressions of the Phillips Curve have focused only on this aspect. However, the foreign output gap can also matter in an indirect way if there exist relevant structural relations in the model not captured by the reduced form considerations. In particular, the foreign output gap may affect the level of natural domestic output and can influence the behavior of the $\Gamma$ term. Furthermore, the degree of openness interacts with the foreign output gap in the determination of the domestic natural output and higher openness may also affect the elasticity of the marginal cost to the two output gaps.

The structural identification of the shocks in the Time-Varying VAR and the impulse response analysis are meant to account for these structural effects, even when the reduced form estimations point against a significant role of the foreign output gap. Zaniboni considers a few different open economy models and he theoretically shows that under standard calibrations of the parameters the coefficient of the foreign output gap in the Phillips Curve is small relative to that of the domestic gap. He also demonstrates that the foreign gap coefficient only slightly increases in function of the degree of openness for realistic ranges of openness. In spite of the smaller role of the foreign output gap in the Phillips Curve, it is still possible to find interesting responses of inflation to a foreign output gap shock. Figure 3 reports the impulse response functions of inflation to the two output gap shocks for the local currency pricing model in Zaniboni using his main calibration and a home bias parameter of 0.8 , which implies a Phillips Curve coefficient of 0.42 and 0.1 for the domestic and foreign output gap respectively. ${ }^{10}$ The impact responses of inflation to a $1 \%$ shock to the domestic and foreign output gap are about $0.7 \%$ and $0.15 \%$ respectively. The response to the foreign gap is always smaller than that to the domestic shock, but it is definitely not negligible and it is also growing in the degree of openness. These simple theoretical results suggest an interesting, albeit less significant, role for global slack too.

\footnotetext{
${ }^{9}$ Inflation depends on marginal costs that, under certain conditions, can be directly linked to the output gap. The slope $\nu$ is a combination of the deep structural coefficients of the model. These coefficients are: the probability firms have of adjusting the price at each period in the Calvo price setting, the elasticity of substitution between home and foreign goods, the intertemporal elasticity of substitution and the labor supply elasticity in the utility function of the consumer, the home bias parameter $h$, and the discount factor $\mu$.

${ }^{10} \mathrm{We}$ add an autoregressive shock to the two output gaps, assuming the standard deviation of these innovations to be half of the standard deviation of the technological shocks and an autoregressive coefficient of 0.8. More details about the model used to generate these impulse response functions are provided in the Appendix.
} 


\section{Our Approach}

We propose to study the GH by using time varying coefficients VAR (TV-VAR) models with stochastic volatilities. We use the estimates of the coefficients of the VAR and the impulse response functions to mainly verify implication 1 and 2 of the GH. However, we can also make some interesting considerations on implication 3 .

For each country in our sample, we estimate the time varying coefficients VAR in (3), in which five variables and two lags have been included in the model.

$$
X_{t}=a_{t}+\sum_{p=1}^{2} B_{t, p} X_{t-p}+\varepsilon_{t}
$$

The vector of variables $X_{t}^{\prime}=\left[\begin{array}{ccccc}\pi_{t} & y_{t}^{d} & y_{t}^{f} & \tau_{t} & i_{t}\end{array}\right]$ includes the 4-quarter domestic CPI inflation $\pi_{t}$, the domestic and foreign real output gaps $y_{t}^{d}$ and $y_{t}^{f}$, the real exchange rate $\tau_{t}$ and a policy (short term) interest rate $i_{t}$. The matrices of coefficients $B_{t, p}$, the intercept term $a_{t}$, and the variance covariance matrix of the innovations $\varepsilon_{t}$ are allowed to vary over time and are freely estimated by the regression model. ${ }^{11}$ The frequency of the data is quarterly and the period sample goes from 1971:1 to 2006:4. Given the sample length, quarterly data provide an adequate amount of observations to estimate these time varying regressions.

The real exchange rate is introduced as a proxy of the import prices used in equation (1). The choice of the real exchange rate finds a justification also from a theoretical point of view. In fact, the term of trade, a term measuring the deviations of import prices from the law of one price, or the real exchange rate are typically present in the Phillips Curve equation of a new Keynesian model. Our measure of real exchange rate is a perfect empirical counterpart of this variable.

We then compute the impulse response functions of the domestic inflation to structural shocks to the domestic and foreign gap and to the real exchange rate at different points in time, identifying the shocks by a recursive Cholesky scheme. Instead of looking only at the time variation of the coefficients, which has been studied by other papers using sub-samples or rolling regressions, we can also statistically evaluate how the shape and significance level of these impulse response functions have changed over the sample. The impulse response functions, along with the time varying coefficients and the behavior of the stochastic variances and covariances of the innovations, provide a much more comprehensive analysis of the changes over time of the structural relations between domestic inflation and the other variables included in the VAR model.

This approach offers three advantages over the simple univariate model in (1). First of all, it allows for a more structural analysis of the implications of the GH. Adding the impulse response functions to the reduced

\footnotetext{
${ }^{11}$ Following Giorgio Primiceri (2005), both the standard deviations and the contemporaneous covariances of the structural innovations are time varying. The technical details of the estimation are presented in the next section and in the Appendix.
} 
form estimates of the VAR can uncover important dynamics otherwise impossible to reveal by the simple univariate regressions. Furthermore, inflation expectations are embedded in the structure of the model itself and they are formed fully exploiting the information contained in all its variables. The second advantage is that the TV-VAR is a technique specifically designed to capture time variations in the relations among the variables of the model. Given the extreme importance of the time dimension in the GH's implications we are testing, it seems opportune to pursue a more reliable assessment of this aspect. Finally, the model estimates also the variance covariance matrix of the shocks at each point in time. This allows us to disentangle possible effects due to changes in the volatility of the shocks from those caused by changes in the structure of the model.

Our empirical analysis is enhanced by a new dataset in which accurate and homogeneous measures of the foreign gap and the real exchange rate for each country are constructed. Following the methodology described by Loretan for the construction of the American real exchange rate, we compute a set of trade-based weights for about fifty countries that we use to aggregate pair-wise exchange rates and national output gaps in order to form the real exchange rate and foreign output gap of each country. Our dataset improves that of IEA by broadening the definition of the world (i.e. increasing the number of countries) used to construct the weights and by extending the time series to the beginning of the 70 's. ${ }^{12}$

The time sample is a sensitive aspect of the results we obtain. Our data cover almost four decades in the post Bretton Woods era; a period characterized by a regime of more flexible exchange rates and the increase in the globalization of the world economy at the heart of the GH intuition. In principle, every country used to construct the trade-based weights could also be used to estimate a TV-VAR, the difficulty of finding consistent series for the short term policy rates going back to the early 70's has prevented us from extending the sample.

\subsection{Estimation of the TV-VAR}

Let $X_{t}$ be a $(n \times 1)$ vector containing observations at time $t$ of the macroeconomic variables of interest. In our case $n=5$ and $X_{t}=\left[\begin{array}{ccccc}\pi_{t} & y_{t}^{d} & y_{t}^{f} & \tau_{t} & i_{t}\end{array}\right]^{\prime}$, for example.

In a general case, variables evolve over time following a time varying VAR

$$
\begin{aligned}
X_{t} & =a_{t}+\sum_{p=1}^{P} B_{t, p} X_{t-p}+\varepsilon_{t} \\
\varepsilon_{t} & =\Omega_{t}^{1 / 2} \omega_{t}
\end{aligned}
$$

\footnotetext{
${ }^{12}$ More details about the construction of the data and the sources used are left for section 4 and the Appendix.
} 
where $a_{t}$ is a $n$-dimensional column vector of intercepts, $B_{t, p}$ is a $(n \times n)$ containing the $p$-lag time-varying autoregressive coefficients, and $\omega_{t} \sim N(0, I)$. Note that the variance covariance matrix of the residuals is also time varying.

Following Cogley and Sargent and Primiceri among others, we postulate a random walk for the evolution of the VAR coefficients:

$$
\Phi_{t}=\Phi_{t-1}+\eta_{t}
$$

where $\Phi_{t}=\left[\operatorname{vec}\left(a_{t}\right)^{\prime}, \operatorname{vec}\left(B_{t, 1}\right)^{\prime}, \ldots, \operatorname{vec}\left(B_{t, p}\right)^{\prime}\right]^{\prime}$.

The covariance matrix of the VAR innovations $\Omega_{t}$ is factored as

$$
\operatorname{VAR}\left(\varepsilon_{t}\right) \equiv \Omega_{t}=A_{t}^{-1} H_{t}\left(A_{t}^{-1}\right)^{\prime}
$$

The time-varying matrices $H_{t} \equiv \operatorname{diag}\left[h_{1, t}, \ldots, h_{n, t}\right]$ and $A_{t}$ are defined as:

$$
A_{t} \equiv\left[\begin{array}{ccccc}
1 & 0 & 0 & 0 & 0 \\
\alpha_{2,1, t} & 1 & 0 & 0 & 0 \\
\alpha_{3,1, t} & \alpha_{3,2, t} & 1 & 0 & 0 \\
\alpha_{4,1, t} & \alpha_{4,2, t} & \alpha_{4,3, t} & 1 & 0 \\
\alpha_{5,1, t} & \alpha_{5,2, t} & \alpha_{5,3, t} & \alpha_{5,4, t} & 1
\end{array}\right]
$$

with the $h_{i, t}$ evolving as geometric random walks $\ln h_{i, t}=\ln h_{i, t-1}+u_{t}$.

Following Primiceri, we postulate that the non-zero and non-one elements of the matrix $A_{t}$ evolve as driftless random walks, $\alpha_{t}=\alpha_{t-1}+e_{t}$, and we assume that the vector $\left[\varepsilon_{t}^{\prime}, \eta_{t}^{\prime}, u_{t}^{\prime}, e_{t}^{\prime}\right]^{\prime} \sim N(0, V)$ where

$$
V=\left[\begin{array}{cccc}
\Omega_{t} & 0 & 0 & 0 \\
0 & Q & 0 & 0 \\
0 & 0 & G & 0 \\
0 & 0 & 0 & S
\end{array}\right] \text { and } G=\left[\begin{array}{ccc}
\sigma_{1}^{2} & & \\
& \ddots & \\
& & \sigma_{n}^{2}
\end{array}\right]
$$

The VAR is then estimated using the Bayesian methods described by Chang-Jin Kim and Charles R. Nelson (1999). In particular, we employ a Gibbs sampling algorithm that approximates the posterior distribution of the model (see the Appendix for details). The priors and the starting values for the VAR coefficients are based on a fixed coefficient VAR estimated over the first 36 quarters of the sample. 


\section{Characteristics of the Dataset}

The first part of the dataset comprises the time evolution of the trade shares and trade-based weights that are used to construct the foreign output gap and effective real exchange rates for each country in the sample. The weights are obtained starting from the time series of the pair-wise import and export flows among a set of about 50 countries which include all the OECD countries, the major Asian economies, and some other emerging countries. ${ }^{13}$ The flows data come from the IMF-DOT database; we cover the sample 1971:1 through 2006:4 at quarterly frequency.

We calculate the weights following the approach of the FED to the construction of the effective exchange rate presented by Loretan. The weights are meant to provide a measure of the relative importance of an international partner for a country. This is achieved accounting both for the direct relations between two countries, given by the relative share of imports and exports from one country to the other, and for the so-called third-party relations, which are used to keep into account the indirect effects due to international competition among countries.

In the second part of the dataset, we construct the five variables used in the estimation of the TV-VAR models. First of all, we collect the domestic output gap for the entire set of countries in the trade-based weights dataset. If the gap is not directly provided by the OECD National Account Statistics, it is constructed as the percentage deviation from the HP-filtered real GDP series taken as a proxy for the potential GDP. The sources for the real GDP are the OECD and the IMF for almost all the countries; the GDP series are first seasonally adjusted. For each of the eighteen countries in the time varying analysis, the domestic output gaps of the full set of countries are then weighted to form the trade-based measure of the foreign gap.

The same procedure applies to the construction of the country-specific real exchange rates. The pair-wise nominal exchange rates, obtained either from the KEYIND database of Global Insight or from the Global Financial Data database, are seasonally adjusted, deflated by the CPI index of the respective country, and aggregated using the same trade-based weights.

We compute the inflation rate as the log-difference of the domestic CPI index relative to the same quarter of the previous year, the 4-quarter inflation has been used by BF while IEA prefer to use the quarter-toquarter inflation in order to reduce the autocorrelation of the residuals of their regressions. The CPI indices usually come from the IMF database or that of the OECD-MEI; the base year is set to 2000 and the series have been seasonally adjusted.

Finally we take short term deposit and money markets interest rates as policy rates. The main source for these is the Global Financial Data database.

\footnotetext{
${ }^{13} \mathrm{~A}$ complete list of the countries can be found in the Appendix. The Appendix defines also the trade-based weights, the formulas applied for the real exchange rate, and describes the data sources more in detail.
} 


\section{Results I: Reduced Form Estimates}

This section and the next present the empirical evidence obtained from the VAR estimates. We study eighteen Western countries and emerging economies; a large variety of sizes and degrees of openness is represented. The countries we analyze are: U.S., U.K., Germany, France, Italy, Spain, Ireland, Denmark, Netherlands, Austria, Switzerland, Canada, Mexico, Australia, Japan, South Korea, South Africa, and New Zealand.

We first check the behavior of the coefficients of the reduced form inflation equation in the VAR. This equation is directly comparable to the regressions typically used in previous literature as empirical counterparts of (1). Limiting our attention only to the first lag of the endogenous variables, it reads

$$
\pi_{t}=c_{t}+\eta_{t} \pi_{t-1}+\beta_{t} y_{t-1}^{d}+\delta_{t} y_{t-1}^{f}+\gamma_{t} \tau_{t-1}+\theta_{t} i_{t-1}
$$

Figures 4 and 5 show the time variation of $\beta_{t}$ and $\delta_{t}$ for the countries in the sample. ${ }^{14}$ The GH suggests that $\beta$ should be positive, but decreasing over time. This is true in Figure 4 only for Germany and, only to some extent, for Italy, Spain, and Japan. In general this coefficient is positive, but only marginally significant for the other countries, or even negative for some of them. On the other hand, Figure 5 shows that $\delta$ is positive and significant only for three countries: U.S., Austria, and Denmark. It is generally not increasing and, overall, only France and Ireland would support the second implication of the GH.

These results do not provide evidence in favor of the GH. The foreign output gap does not seem to play a significant role and the second hypothesis is fully satisfied only by Ireland. Even in those countries like Italy, Japan, or Denmark in which $\delta$ was more significant at the beginning of the sample, the effects of the foreign output gap diminish over time rather than increase. However, we find that the domestic output gap is still relevant for about half of the countries we analyze. When positive, the median estimates of $\beta$ typically range between .1 and .2 , which are values consistent with the standard parameterization of the New Keynesian model used in Section 2.2. Milani estimates a full structural model for the G7 economies, all included in our sample too, and he obtains results qualitatively in line with our estimates.

From these figures, the lack of a meaningful relation between inflation, output gaps and globalization emerges quite clearly. Any common time profile of the coefficients is missing and the time variation in each country seems to be due more to the specific characteristic of its economy rather than being related to the degree of globalization per se. ${ }^{15}$

The third implication of GH about $\gamma$ is studied in Figure E1. The definition of real exchange rate we use

\footnotetext{
${ }^{14}$ The plots of $\gamma_{t}$ are reported in Figure E1 in the Complementary Material section instead.

${ }^{15}$ Another way to use the reduced form estimates to study the GH predictions is to analyze the time varying correlations between inflation and the two output gaps. The same kind of outlook and conclusions are obtained from this analysis too.
} 
implies that an increase of the index corresponds to a domestic appreciation. According to the GH, $\gamma$ should be negative and increasing in absolute value. Even though $\gamma$ shows often the right sign when significant, it is difficult to find a common pattern across countries in time evolution also of this coefficient. Only France and Ireland and, to a smaller extent, Spain and Germany satisfy the prediction of the GH.

Our estimates also show that the volatility of inflation and policy shocks has decreased in the last two decades (not reported here). The declining volatility of the inflation process may raise some concern about the possibility of effectively estimating the coefficients of domestic and foreign output gaps in the Phillips Curve when adaptive expectations are used. For instance, in the estimates by IEA, not only $\delta$ is neutralized, but also $\beta$ is often overturned. The use of stochastic volatilities in the TV-VAR directly assesses and attenuates this kind of problem.

Our reduced form results consistently with the view expressed especially by IEA would reject the GH. The TV-VAR approach, however, allows us to carry out a more thorough analysis of the relation between inflation and the two output gaps by taking into account some new information missing from the simple reduced form univariate studies. We turn to this new information in the next section.

\section{Results II: Structural Evidence}

The advantage of using a VAR approach instead of a plain univariate regression is that also some considerations on the structural relations between variables of the model can be made. Even though the reduced form Phillips Curve does not support the GH implications, changes in those relations might be disclosed by the impulse response functions of inflation to the structural output gap shocks. Once the analysis is conducted from the structural perspective, the contribution of the foreign output gap to the dynamics of inflation livens up again. We obtain some new evidence that definitely undoes the clear-cut conclusions from the reduced form analysis and that can be interpreted as in favor of the GH, especially of hypothesis 2 .

\subsection{Identification Scheme}

A natural way to map the first two implications of the GH into the impulse response functions is to associate the response of inflation to a domestic output gap shock to the prediction for $\beta$ and the response to the foreign gap shock to the prediction for $\delta$. Obviously, results could depend on the specific identification scheme chosen to identify the structural shocks. Our identification strategy is based on the following observations.

We rely on a Cholesky recursive decomposition of the VAR reduced form residuals covariance matrix $\Omega_{t}$. The Cholesky decomposition is usually regarded as a convenient way to derive the structural VAR starting from the reduced form estimates and it has been extensively used in the empirical VAR literature 
for monetary policy analysis. The choice of the ordering of the variables in the decomposition is the key feature of the identification assumptions and this literature provides some useful guidance in the choice of the ordering in our model too.

We start separating the interest rate, $i$, and the real exchange rate, $\tau$, from the other three real variables. The policy rate is normally ordered as last in the monetary VAR literature, this is used as an identification assumption to isolate the monetary shock. It is assumed that the interest rate does not affect output and inflation in the same period, while at the same time it is able to respond on impact to them. We follow Eric M. Leeper, Christopher A. Sims, and Tao Zha (1996), Lawrence J. Christiano, Martin Eichenbaum, and Charles L. Evans (1999), and Primiceri among others in this choice. Being essentially a financial variable free to adjust continuously, it seems relative safe to order the exchange rate as fourth. The correct relative position of these two variables is hard to define a priori, it would depend on the monetary policy characteristics of a country. For a country with a central bank concerned with stabilization of the exchange rate, as for example smaller and export oriented economies, $i$ should be ordered as the last variable; for bigger and closer countries, as, for example, the U.S., it could be more reasonable to order $\tau$ as last. We must notice this does not really matter for the impulse response functions of $\pi$ to the two output gaps, which is what we are mainly interested in here, and, for this reason, we keep $i$ in the last position in our applications.

We turn then to the relative order of the three real macro variables: the inflation rate, $\pi$, and the two output gaps, $y^{d}$ and $y^{f}$. It is quite reasonable to assume that the foreign output gap is less responsive to the domestic output gap than vice versa. This is definitely true for a small open economy, and this basically refers to most of the countries in our sample; it might be a less suitable assumption for large economies such as the U.S., but it turns out that the impulse responses of inflation to foreign gap shocks are generally less sensitive to the chosen ordering for those large countries. In terms of identification assumptions, these observations lead us to consider an ordering in which $y^{f}$ comes before $y^{d}$.

The last crucial element of the identification at this point is the relative position of $\pi$ and $y^{d}$. Primiceri uses the same TV-VAR framework to study a small macro model for the U.S. monetary policy. He includes only $\pi, y$, and $i$ in his VAR and considers the relative ordering of $\pi$ and $y$ as a normalization once the monetary shock has been identified. He is interested in the responses of the variables to policy shocks and his results are not affected by the specific choice about the ordering. The relative position of $\pi$ and $y^{d}$ does not actually introduce large differences in the responses of inflation to the domestic output gap shocks in our framework either.

We therefore propose as baseline identification scheme the ordering $\left(\pi y^{f} y^{d} \tau i\right)$, in which the impact responses of $\pi$ to the two output gap shocks are constrained to zero. A justification of this specification is that the effects of these shocks on inflation mat take place with some delay due, for example, to price stickiness or 
to the slower transmission mechanism of international shocks. As a robustness check, we take into account this second identification ordering $\left(y^{f} y^{d} \pi \tau i\right)$, which can be considered slightly less conservative since no restrictions on the impact responses of inflation are imposed. ${ }^{16}$

Our identification strategy is similar to that used by Gert Peersman and Frank Smets (2003) to study the monetary policy transmission in the Euro Area. They treat the foreign output as an exogenous variable, while we keep it as endogenous in the VAR, and they prefer to order the exchange rate last. This is a good assumption for Europe, but not in general for smaller economies. In fact, Benoît Mojon and Peersman (2003) adopt a specification like ours when studying the transmission inside single countries of the European Union.

\subsection{Impulse response functions and the GH}

\subsubsection{Responses to the Output Gap Shocks}

As an illustrative example, we focus first on the U.S. in Figure 7. The figure illustrates the response functions of inflation to a unit shock to the domestic and foreign output gaps for the baseline identification. ${ }^{17}$ The responses are presented for the sample 1980:3 to 2006:4 and for a sixteen-quarter horizon. The solid, lightgrey lines are the median response for each period; the shaded surfaces indicate significance of the posterior distribution of the responses at the $14 \mathrm{th} / 86 \mathrm{th}$ percentiles (light blue) and at the 5th/95th percentiles (darker blue).

This figure shows that both output gaps matter for the dynamics of U.S. inflation. The response functions are nicely hump-shaped and they can be significant up to eight quarters in many periods for the domestic shock and for four to six quarters for the foreign shock. The responses at the beginning of the sample are stronger than those observed after the nineties in both cases, even though the domestic output gap shock generates more persistent responses. This outcome is broadly consistent with the theoretical impulse response functions reported in Figure 3.

We can now broaden the look to the full set of countries in Figures 8 and 9, which show the responses of inflation to a positive shock to the domestic and foreign output gap respectively. ${ }^{18}$ With a few exceptions, among which Austria is the most evident, the responses to the domestic gap shocks are mostly positive and, typically, significant in the first quarters after the shock; they revert then to zero after two years. Turning to

\footnotetext{
${ }^{16}$ These two identification schemes represent the two extremes of the range of possible permutations of the three real variables of the VAR. A third option would be the ordering $\left(y^{d} \pi y^{f} \ldots\right)$, but it seems less plausible than the two we consider. It would basically generate the same outcomes as the ordering $\left(y^{f} y^{d} \pi \ldots\right)$ and there is no particularly valid reason for assuming that inflation does not contemporaneously respond to the domestic output gap, on the one hand, while responding to the foreign gap on the other.

${ }^{17}$ The response functions to unit shocks can be consistently compared across time and across shocks because normalized with respect to the size of the impulses. The responses can be simply interpreted as proportional to a one percent shock to the output gaps. Estimating the VAR with stochastic volatilities, the unit shocks provide the correct way to disentangle the effects due to changes in the magnitude of the shocks form those due to changes in the structural relations of the variables.

${ }^{18}$ These two figures share the same characteristics as Figure 7.
} 
the responses of inflation to the foreign gap shocks in Figures 9, we observe positive and significant responses very robustly across countries and periods. As mentioned above for the U.S., these responses are somewhat less persistent.

A first important conclusion is suggested by this set of figures. In spite of the small significance of $\delta$ found in the reduced form Phillips Curve regressions, the impulse response functions reveal the structural importance of the foreign output gap for the dynamics of inflation. Not only does the foreign output gap matter, but it also has effects comparable in magnitude to those of the domestic output gap. This evidence is in line with the theoretical implications of the open economy New Keynesian models discussed in Section 2.2; actually, the effects we find are even larger than those predicted by the theory for standard calibrations as reported in Figure 3. Very similar figures and conclusions are obtained under the second identification scheme, as illustrated in Figures E2 and E3 in the Complementary Material section. The most interesting difference is the negative impact response of the Canadian inflation to the foreign output gap shock. ${ }^{19}$

Figure 10 illustrates that, as one would expect, the responses of inflation to real exchange rate shocks are mostly negative, in particular in the first eight quarters after the impulse (Austria and, to some extend, Australia and Denmark are the only exceptions). The responses are quite significant too, even though smaller in magnitude than those found for the two previous shocks. Downward shift effects on domestic producer price inflation due to low import prices have been recently documented by Auer and Fischer for the U.S. and Europe too. Even though not directly comparable to their results, our estimates definitely point in the same direction. ${ }^{20}$

In spite of the undeniable role of the foreign output gap, the time predictions of the GH seem to fail because the importance of the foreign output gap does not grow at the expense of the domestic gap over time. In particular, a dynamic role of the degree of openness related to the time evolution of the response functions does not come to light from the analysis at individual country level, yet a cross-section analysis could help to reveal a positive relation between openness and the effects of the foreign gap. Evidence in this respect is provided by the panel analysis in the next section.

\subsubsection{Panel Analysis}

Confirmed that the foreign output gap can affect domestic inflation, we want to test for the main implication of the GH, which is the positive relation between globalization and the effects the of global economic slack

\footnotetext{
${ }^{19}$ The section Complementary Material replicates most of the output also for the alternative identification ordering. In particular, Figures E2 and E3 correspond to Figures 8 and 9; Tables E1-E3 correspond to Tables 4-6.

${ }^{20}$ Auer and Fischer find, for example, an annual downward effect between 40 and 60 basis points on the aggregate PPI inflation of the U.S. caused by import competition from low wage countries. In our estimates, the accumulated response of inflation to a unit real exchange rate shock approximately ranges between 5 and 10 basis points in the first year after the shock. Their effect would be roughly consistent with the effects of a $5-8 \%$ annual domestic real appreciation in our framework.
} 
on inflation. As globalization grows, the foreign output gap is expected to progressively become the driving force of domestic inflation. This prediction has usually been verified studying the change over time of the coefficients in (10). We check instead for a formal link between the response functions in Figures 8 and 9 and openness and business cycles integration estimating a set of panel regressions in order to provide a more accurate quantitative assessment of the GH predictions. As explained above in Section 2.1, the degree of openness and the business cycles integration can be considered two adequate indicators of globalization in our framework.

A first set of panel regressions is specified as in (11)

$$
m_{i t}=c+\lambda_{0 i}+\lambda_{1} \text { open }_{i t}+\lambda_{2} \text { corr }_{i t}+\lambda_{3} \text { trend }_{t}+\lambda_{4} m_{i t-1}+v_{i t}
$$

in which the index $i$ identifies the countries and $m_{i t}$ represents a set of measures meant to capture some relevant characteristics of the impulse response functions related to the GH predictions to be tested. We use the average response of $\pi$ to the two output gap shocks and the four-year cumulative responses as the two main $m_{i t}$ variables in the assessment of predictions 1 and 2. As a further robustness check, we also consider the same measures for the difference between the response functions to the two shocks. ${ }^{21}$

These measures are regressed on the degree of openness of the country, open $i t$, and the correlation of the reduced-form residuals of the $y^{d}$ and $y^{f}$ equations of the VAR, corr ${ }_{i t}$. Openness is measured as the ratio to GDP of the sum of imports and exports and it is reported in Table 3 by half-decade since 1980 to 2006. The correlation term, illustrated in Figure 6, is used to measure business cycles integration and it expresses another measure of economic integration complementary to openness. We also include in the regression a constant, $c$, fixed effects, $\lambda_{0 i}$, a time trend, $\operatorname{trend}_{t}$, and in some of the specifications also the lagged value of the independent variable, $m_{i t-1}$. The responses of inflation to both output gap shocks clearly follow a negative trend, characterized by weaker responses in the second part of the sample. There is large agreement that the slope of the Phillips Curve with respect to the domestic output gap has become flatter over time and this seems to be the case for the foreign gap as well. It is important to control also for the time trend in the regressions since it may undermine some of the effects we are interested in.

In addition to openness, globalization is also related to the degree of integration of the domestic business cycles with the global economy. The introduction of $\operatorname{corr}_{t}$ in (11) provides some first evidence about the importance of this dimension of globalization in the context of the globalization hypothesis. In order to further explore the role of business cycles coordination, we exploit cross-section differences in it to assess

\footnotetext{
${ }^{21}$ We check the estimates of the panel regressions with four other definitions of $m_{i t}$ : the cumulative responses based on the positive points only; the cumulative response based on the significant, positive points of the responses; the percentage of significant, positive points in the responses; and the percentage of positive points in the responses. We obtain results very similar to those presented in Tables 4-6.
} 
whether the effects of openness on the relation between inflation and foreign gap are stronger for more integrated countries. As shown in Table 2, the sample correlation between domestic and foreign gaps is quite uneven across countries; therefore, we split them into a high (more integrated) and a low (less integrated) correlation group and we allow the slope of open $_{i t}$ to differ between the two groups in the panel regressions. The new regression equation is specified as in (12)

$$
m_{i t}=c+\lambda_{0 i}+\lambda_{1} D \times \text { open }_{i t}+\lambda_{2}(1-D) \times \text { open }_{i t}+\lambda_{3} \text { corr }_{i t}+\lambda_{4} \text { trend }_{t}+\lambda_{5} m_{i t-1}+v_{i t}
$$

where $D$ is a dummy variable equal to 1 for the countries with correlation greater than .5 in Table 2 and zero otherwise. ${ }^{22}$

The estimates of the panel regressions are presented in Tables 4-6 for the baseline identification ordering. Similar results are reported in the Complementary Material section for the second ordering in Tables E1-E3. The results shown on the left side of the tables refer to equation (11), the output for equation (12) is on the right side. Columns (a) and (b) are estimated by OLS; columns (c) use the Arellano-Bond estimation procedure for dynamic panels. The estimates for the average response of inflation are reported under the heading $M E A N$ and for the cumulative response under $C U M{ }^{23}$

Before analyzing the estimates of the coefficients of open, two observations about the other coefficients are noteworthy. As expected, the trend coefficient is negative, even though its statistical significance is only limited. The decrease in the cumulative responses ranges from 4 to 6 basis points per year when significant. Although this is a relatively small annual rate, it implies a quite large long-run effect. The second observation is that the autocorrelation coefficients in the dynamic panel regressions show that the $m_{i t}$ variables are quite persistent. After controlling for a time trend and autocorrelation, the openness coefficient gets typically smaller.

Prediction 1 is studied in Table 4. The estimates of the table do not corroborate this prediction of the GH. The estimates in equation (11) may seem, at least in part, in line with the expectations of a negative coefficient for open, yet they are never significant. In fact, in equation (12), the coefficients are negative only for the group of less integrated countries. On the contrary, the estimates for the highly integrated countries turn consistently positive, even though for neither group the estimated coefficients are significant at all. Globalization and economic integration do not seem to promote the departure of the Phillips curve from the domestic output gap. The same conclusion is reinforced by the estimates of the coefficient of corr

\footnotetext{
22 The results of the regressions presented below are robust to changing the threshold of the correlations to .4 or .6.

${ }^{23}$ Robust White period standard errors are computed to correct for arbitrary autocorrelation within cross-section in the residuals. The instruments used to obtain the Arellano-Bond estimates in columns (c) include up to the fifth lag of the dependent variable and $\Delta$ open $_{t}$. It is plausible to assume that openness is strictly or, at least, sequentially exogenous with respect to the responses of inflation to the two output gap shocks. In these regressions we are obviously assuming strict exogeneity.
} 
which are always positive and often significant too.

Prediction 2 is presented in Table 5. In this case, we find interesting evidence in favor of this prediction of the GH from equation (12). The estimates of the openness coefficient in equation (11) are non-positive and non-significant. However, the estimates for the highly integrated countries in equation (12) are positive and significant at $5 \%$ level in three out of six specifications and at $10 \%$ level in five specifications, while those of the moderately integrated countries are basically always negative and also statistically significant in specification (c). Economic integration is crucial for the identification of this effect of the degree of openness; the openness channel is effective only if a country is also sufficiently integrated into the global economy. Economic integration and openness are complementary, and not overlapping, measures of globalization in our analysis. The importance of economic integration is strongly reinforced by the significant and positive estimates of the coefficient of the corr term.

We provide a simple evaluation of the economic magnitude of these effects for the $C U M$ estimates. An openness coefficient equal to 1 would imply a 10 basis points larger cumulative response of inflation to a $1 \%$ shock to the foreign output gap for every 10 extra percentage points in the openness index. In periods of high volatility, the typical standard deviation of these shocks is around $.3-.4 \%$, which would correspond to an increase in cumulative inflation by $3-4$ basis points. Given the estimates for the three specifications in Table 5, these figures imply that a slightly more open country would have a higher cumulative inflation in response to the same foreign output gap shock roughly ranging from 5 basis point up to 12 points. This effect amounts to one fifth of the average response for the highly integrated countries. Table 3 shows that a ten percentage variation in the openness degree of a country can be considered a very large change even over three decades; however, this would be a much more normal difference across countries since the openness index goes from 20 to more than 100 percent. This explains why adding the cross-section dimension to the analysis allows us to detect the effects of openness in the panel regressions, while those effects do not come to light from the simple time analysis.

Also Table 6 assesses Prediction 2. It reports the estimates for the relative effects of the two shocks, measured by the difference between the response functions to the $y^{f}$ and the $y^{d}$ shock respectively. As in the previous case, the difference increases in openness only for the more integrated countries. The results are in line with those in the previous table, although slightly weaker, as also the estimates of the corr coefficient show.

As a robustness check, Tables E1-E3 present the same estimates for the second ordering of the Cholesky identification of the VAR. Consistent results are obtained but with one noteworthy difference. The estimates of the openness coefficients for the moderately integrated countries are now the same as those for the more integrated ones. For this reason, it is somewhat easier to observe coefficients with the expected sign in the 
regressions with the exception of specification (c) for the foreign shock and for the difference in the two shocks, in which distinguishing between the two groups of countries is still necessary to find the predicted effects. However, the magnitude of these effects does not change from one identification scheme to the other and the importance of the economic integration, independently of the degree of openness, is confirmed by the estimates of the corr coefficient.

\section{Conclusions}

The goal of this paper is to empirically assess whether the implications of the globalization hypothesis for domestic inflation holds. In particular, we focus on the relation between global slack, represented by the foreign output gap, and inflation. The majority of the previous literature has tackled this question comparing the coefficients of univariate regressions of the Phillips Curve over different subsamples under the assumption that globalization has pervasively increased in the past decades. Mixed empirical evidence is typically found. Our approach aims to provide a more comprehensive analysis of this issue based on some structural considerations. First, we estimate time varying coefficients VAR models for a broad set of countries, using a homogenous data set covering the sample from 1970 to 2006. Second, we use the impulse response functions of inflation to the domestic and foreign output gaps in a panel analysis in order to quantitatively study the relation between globalization and the effects of the foreign output gap on domestic inflation. From the results of our analysis, we draw two main conclusions.

The first conclusion is that the inflation response functions to foreign output gap shocks show that global economic slack affects the dynamics of domestic inflation in many countries. For this reason, using the reduced form estimates of the VAR to assess the relation between inflation and foreign output gap would be quite misleading. Despite the coefficients of the foreign output gap in the inflation equation of the VAR being often small and not particularly significant, the foreign output gap can definitely have a significant role at structural level. This conclusion is robust across countries, periods and specifications of the identification scheme. The structural analysis shows that univariate studies of the Phillips Curve would wrongly underestimate the potential role of globalization.

The second conclusion is that, in spite of this evidence, the predictions of the GH find only partial support in the panel regression analysis. The panel estimates show that Prediction 1 fails, whereas Prediction 2 holds but with a positive effect of openness only for countries economically more integrated into the global economy. Therefore, we highlight the importance of business cycles integration in studying the relation between inflation and foreign output gap. Not only is integration associated to a higher sensitiveness of domestic inflation to the foreign gap, but also it is a necessary condition to observe the expected positive 
effects of openness on this relation. Furthermore, these effects require substantially large changes in openness in order to be economically significant. For this reason, the small historical increase in the openness indexes of the countries we analyze, only five percent on average, does not allow any clear effect to emerge. This is evident when conducting the cross-section analysis: In this case, the large cross country heterogeneity leads to significant differences in the link between domestic inflation and the foreign output gap. 


\section{APPENDIX}

\section{A The Dataset}

This Appendix provides further details about our dataset. We only focus on data sources and the main procedure to obtain the real exchange rates and the foreign output gaps. A full description of the dataset and country specific information are given in the note "The construction of a global trade-based dataset" which is available from the authors' webpage, along with all the matlab codes necessary to construct the database.

\section{A.1 Countries}

We run the TV-VAR for eighteen countries: U.S., U.K., Germany ${ }^{24}$, France, Italy, Spain, Ireland, Denmark, Netherlands, Austria, Switzerland, Canada, Mexico, Australia, Japan, Korea, South Africa, New Zealand.

In addition to these eighteen countries, the other countries included in the sample for the trade-based weights are: Belgium, Luxembourg, Norway, Sweden, Finland, Greece, Iceland, Portugal, Turkey, Yugoslavia (Croatia and Slovenia after 1993), Argentina, Brazil, Colombia, Peru, Venezuela, Israel, Hong-Kong, India, Indonesia, USSR (Russia, Latvia and Lithuania after 1993), China, Czechoslovakia (Czech Republic and Slovakia after 1993), Hungary, Poland.

\section{A.2 Weights and other formulas}

The formula for the imports, exports, and third party weights $\left(w^{m}, w^{x}\right.$, and $w^{3}$ respectively) necessary to compute the foreign output gaps and the effective real exchange rates are the following:

$$
\begin{aligned}
w_{i, j, t}^{m} & =\frac{M_{i, j, t}}{\sum_{j=1}^{N_{t}} M_{i, j, t}} \\
w_{i, j, t}^{x} & =\frac{E X_{i, j, t}}{\sum_{j=1}^{N_{t}} E X_{i, j, t}} \\
w_{i, j, t}^{3} & =\sum_{k \neq j, \neq i}^{N_{t}} w_{i, k, t}^{x} \frac{w_{k, j, t}^{m}}{1-w_{k, i, t}^{m}}
\end{aligned}
$$

where $M_{i, j}$ and $E X_{i, j}$ indicate imports from country $j$ to country $i$ and exports from country $i$ to country $j$. The presence of a time dependent $N_{t}$ in the summations easily accommodates the possibility of a varying

\footnotetext{
${ }^{24}$ East Germany is added to West Germany after the 1992 unification.
} 
pool of countries. The weights are then aggregated as in (13)

$$
w_{i, j, t}=0.5 w_{i, j, t}^{m}+0.5\left(0.5 w_{i, j, t}^{x}+0.5 w_{i, j, t}^{3}\right)
$$

The real exchange rate index $\hat{I}_{i, t}$ for country $i$ at time $t$ is obtained by combining these weights with the pair-wise exchange rates. We follow Loretan and apply the next formula

$$
\hat{I}_{i, t}=\hat{I}_{i, t-1} \prod_{j=1}^{N_{t}}\left(\frac{\hat{e}_{i, j, t}}{\hat{e}_{i, j, t-1}}\right)^{w_{i, j, t}}
$$

where $\hat{e}_{i, j, t}$ is the real exchange rate between country $i$ and country $j$ defined as

$$
\hat{e}_{i, j, t}=e_{i, j, t} \frac{P_{i, t}}{P_{j, t}}
$$

In (14), $P_{i, t}$ is the CPI of country $i$ at period $t$ and $e_{i, j, t}$ is the nominal exchange rate between country $i$ and $j$ expressed as the price of one unit of currency $i$ in terms of currency $j$. So $\hat{e}_{i, j, t}$ can be defined as the value (or the price) of country $i$ bundle of goods in terms of country $j$ basket. Currency $i$ (good $i$ ) becomes more valuable relative to its $j$ 's counterpart when $e_{i, j}\left(\hat{e}_{i, j}\right)$ increases.

Whenever an official output gap measure is not available for a country, the potential output of that country is first obtained applying the HP filter to the real GDP; we then compute the output gap for country $i$ as the percentage deviation of the actual GDP from its potential

$$
g a p_{i, t}=\frac{g d p_{i, t}}{\text { pot }_{i, t}}-1
$$

The relevant foreign output gap for country $i$ is finally computed as the weighted average of the domestic output gap of all the other countries in the sample, using the weights in (13).

\section{A.3 Sources}

The main sources for the data in this work are the OECD National Accounts Statistics (NAS) and Economic Outlook (EO), the OECD Main Economic Indicators (MEI), Global Insight (GI), and Global Financial Data (GFD).

Trade Flows. For all countries and throughout the entire sample the IMF Direction of Trade (DOT) provides the pair-wise trade flows among the countries in the sample. The data are available from 1960:1 to 2006:4, but the sample is reduced to 1970:1 to 2006:4 when working with GDP data and other series due to the shorter availability of most of these series. The flows are measured in current U.S. dollars for all the 
countries. Notice that DOT treats Belgium and Luxembourg as separate countries only after 1997 and that Germany is defined as West Germany alone before the 1991 reunification. We necessarily keep the same definitions for the other data too.

Real GDP. EO provides the output gaps for eight countries: U.S., U.K., Canada, Australia, France, Germany $^{25}$, Italy, and Japan. OECD follows a procedure very similar to ours to construct the output gap since our measure almost perfectly coincides with theirs for these countries. For the other countries, the real GDP series is used as explained in the previous section. The series are generally already seasonally adjusted, but, if not, we apply Census x12 to them. NAS covers all the OECD countries for the entire sample: Denmark, Netherlands, Norway, Sweden, Switzerland, Canada, Japan, Finland, Greece, Iceland, Ireland, Portugal, Spain, New Zealand, Mexico, Honk-Kong, Korea, Belgium, Luxembourg, South Africa, and Austria. ${ }^{26}$ The other countries require some more manipulations; different sources (mostly GFD and Datastream) are combined to get the most consistent measure of GDP for the longest possible period. Time sample limitation is the main problem in these cases, with series of the emerging countries and youngest nations starting only in the late 80's. Yugoslavia, USSR, and Czechoslovakia are dropped from the output gap sample for lack of quality in their data. For their recent importance in the world economy, China and India are maintained for the entire sample even though their quarterly data start only in the 90's; a fitting on the annual data is implemented. The source for Chinese data is China Marketing Research Co.

Nominal GDP. The nominal GDP data are necessary only to compute the measure of openness of the country presented in Figure 2 and Table 3, since the trade flows are expressed in current dollars. Therefore, we need to cover a much narrower sample of countries. However, given the real GDP series, the CPI and the exchange rates, we can construct the nominal series in dollar for most of the countries in the larger sample. Comparison with OECD_MEI and GFD data confirm the reliability of these series.

Nominal Exchange Rates. We use the U.S. dollar as pivotal currency for the bilateral exchange rates between the U.S. and the other countries in the sample; this allows the creation of a pair-wise dataset for each country. The main sources of these series are the KEYIND data base of GI and the GFD web data base. The data are originally reported in units of a currency necessary to buy one U.S. dollar and we express the exchange rates in units of foreign currency necessary to buy one unit of domestic currency. To avoid shifts in the definition of the accounting unit of the numeraire, we always use the most recent monetary unit adopted by a country as reference unit. If this is not possible, because of a change in both the accounting unit and the political definition of a country, we adopted ad hoc solutions. ${ }^{27}$ Finally, the exchange rates in

\footnotetext{
${ }^{25}$ Only after the unification. For the years before 1992 the West Germany output gap is used.

${ }^{26}$ Austria requires an integration with data from GFD.

${ }^{27}$ These shifts in definition are typical for emerging economies and the new nations founded during the 90 's. The note online provides a full description of them.
} 
dollar terms are seasonally adjusted by using Census x12. The countries members of the EU switch to the common currency in 1999.

CPI. We set 2000 as the base year; the average of the CPI indices at that year is set to 100 . The series are mainly from IMF (through GI), OECD_MEI is the main alternative source; some of them are from GFD too. We seasonally adjust them using Census x12; this adjustment is relevant only for few of the countries from GFD. In particular, the series for Germany and U.S., Slovakia and Czech Republic, Brazil, Hungary, and Poland are from MEI, while those for the Russian Republics, Slovenia, Croatia, and Hong Kong are from GFD. China needs again a special treatment. Since 1987 a mixed of MEI and China Marketing Research Co data is used at quarterly frequency; before that we use annual figures for the CPI as we did for the GDP.

Interest Rates. Suitable interest rate series are usually available only starting from the 80 's for most of the countries in our sample. For this reason, we focus only on the eighteen countries in the TV-VAR analysis. We select and construct the series following two criteria. First of all, short term interest rates are required. So, when possible, we take the 3-month treasury bill yields. If this type of series is not available for a country, we usually take a short term interbank or deposit rate. We obviously prefer continuous and homogenous series, however, in some cases we had to merge together more than one series in order to span the entire sample, in particular for the earlier years. GFD is the most useful source for this variable. Treasury bill rates are used for Japan, U.S., U.K., France, Germany, Australia, Canada, Italy, Belgium, Netherlands, Ireland, and South Africa. Interbank rates are used for Switzerland, Korea, Denmark, Mexico, and Spain. A mixed series is used for Austria and New Zealand.

\section{B The Theoretical Model in Section 2.2}

This appendix provides some details about the model used to generate the theoretical impulse response functions presented in Section 2.2 and Figure 3. The model is based on one of the examples studied by Zaniboni (2008) and a full derivation of it can be found in his paper.

The model is a standard two-country open economy New Keynesian model. The structure of the model is perfectly symmetric in the two countries and it comprises three main parts for each country. The three parts are the following:

1. Preferences are defined over consumption and labor. The utility function is separable in the two arguments and constant risk aversion is assumed. Consumption is defined in final goods, which is an aggregate of domestic and foreign intermediate goods. These tradable goods are imperfect substitutes and it is assumed that households are biased toward domestic goods. The degree of openness of a country is inversely related to the degree of home bias. Finally, it is assumed that international 
financial markets are complete. This component of the model is represented by a standard open economy Euler equation.

2. While the final good market is perfectly competitive, intermediate-good producers are monopolistically competitive and they set prices a la Calvo. Non-tradable goods are not included in the model for simplicity. Producers can price discriminate between domestic and foreign market and the exporting price is set in local-currency prices, which implies that deviations from the law of one price are possible given nominal price rigidities. This block produces one Phillips Curve equation for each type of inflation in a country: the inflation for domestically-produced goods, the imported-good inflation, and the overall CPI inflation.

The relevant Phillips Curve for our study is obviously the CPI inflation equation, which would be very similar to equation (2) in the main body of the paper. For the domestic country it reads

$$
\pi_{t}=\mu E_{t} \pi_{t+1}+\nu\left[(1-h) y_{t}^{d}+h y_{t}^{f}\right]+\Phi z_{t}
$$

where the notation is the same as in (2), with the exception of the shift term $\Gamma_{t}=\Phi z_{t}$. In this specification of the model, $z_{t}$ represents the deviations from the law of one price of the imported intermediate goods and $\Phi$ is a combination of the structural parameters of the model.

The slope of the relation between output gaps and inflation depends on the home bias parameter $(1-h)$, set to 0.8 , and the coefficient $\nu$, which summarizes the responsiveness of inflation to the marginal cost and of the marginal cost to the output gap. This coefficient is a function of the Calvo probability of adjusting prices (set to 0.25 ), the elasticity of substitution between home and foreign goods (set to 1), the risk aversion parameter (5), the inverse of the Frisch elasticity (3), the preferences discount factor $\mu$ (0.99), and the home bias parameter too. The coefficient $\Phi$ determines the sensitiveness of inflation to import prices. As well as $\nu$, it depends on the Calvo probability of adjusting prices, the elasticity of substitution between home and foreign goods, the risk aversion parameter, the preferences discount factor $\mu$, and the home bias parameter. Under this calibration, the domestic and foreign output gap coefficients are 0.42 and 0.1 respectively.

The output gap is defined as the difference between output and its flexible-price potential level. In this kind of model, the flexible-price output of a country depends on the output of the other. This is the main type of structural link between foreign output gap and domestic inflation that theoretically justifies the globalization hypothesis. Finally, we include an exogenous shock to the output gap equation in order to plot the impulse responses in Figure 3. 
3. The model is closed by a Taylor rule, with inflation and output gap parameters respectively set to 1.5 and 0.125. The exogenous innovations are three: a technology, a monetary, and the output gap shock. They are assumed to follow an $A R(1)$ process with autoregressive parameter equal to 0.8 . Finally, the two sides of the model are connected by an equation for $z_{t}$, the deviations of import prices from the law of one price, defined as the difference between the foreign currency price of the foreign good converted into domestic currency and the domestic currency price of the imported foreign good.

The model is log-linearized around a zero-inflation steady state and the solution is found using gensys by Chris Sims. The impulse response functions reported in Figure 3 are quite robust to nearby calibrations.

\section{Time-Varying Model}

The reader can make reference to Francesco Bianchi, Haroon Mumtaz, and Paolo Surico (2009) for more details about the estimation procedure of the time varying VAR model.

\section{C.1 Priors}

\section{VAR coefficients}

The prior for the VAR coefficients is obtained via a fixed coefficients VAR model estimated over the sample 1971:1 to $1979: 4 . \Phi_{0}$ is therefore set equal to

$$
\Phi_{0} \sim N\left(\hat{\phi}^{O L S}, V^{O L S}\right)
$$

\section{Elements of $H_{t}$}

Let $\hat{v}^{\text {ols }}$ denote the OLS estimate of the VAR covariance matrix estimated on the pre-sample data described above. The prior for the diagonal elements of the VAR covariance matrix is as follows:

$$
\ln h_{0} \sim N\left(\ln \mu_{0}, I_{n}\right)
$$

where $\mu_{0}$ are the diagonal elements of $\hat{v}^{\text {ols }}$.

\section{Elements of $A_{t}$}

The prior for the off-diagonal elements $A_{t}$ is

$$
A_{0} \sim N\left(\widehat{\alpha}^{o l s}, V\left(\widehat{\alpha}^{o l s}\right)\right)
$$


where $\widehat{\alpha}^{\text {ols }}$ are the off-diagonal elements of $\hat{v}^{\text {ols }}$, with each row scaled by the corresponding element on the

diagonal. $V\left(\widehat{\alpha}^{o l s}\right)$ is assumed to be diagonal with the diagonal elements set equal to 10 times the absolute value of the corresponding element of $\widehat{\alpha}^{\text {ols }}$.

\section{Hyperparameters}

The prior on $Q$ is assumed to be inverse Wishart

$$
Q_{0} \sim I W\left(\bar{Q}_{0}, T_{0}\right)
$$

where $\bar{Q}_{0}$ is assumed to be $\operatorname{var}\left(\hat{\phi}^{O L S}\right) \times 10^{-4}$ and $T_{0}$ is the length of the sample used for calibration.

The prior distribution for the blocks of $S$ is inverse Wishart:

$$
S_{i, 0} \sim I W\left(\bar{S}_{i}, K_{i}\right)
$$

where $i=1 \ldots n$ indexes the blocks of $S . \bar{S}_{i}$ is calibrated using $\hat{a}^{\text {ols }}$. Specifically, $\bar{S}_{i}$ is a diagonal matrix with the relevant elements of $\hat{a}^{\text {ols }}$ multiplied by $10^{-3}$.

Following Cogley and Sargent, we postulate an inverse-Gamma distribution for the elements of $G$,

$$
\sigma_{i}^{2} \sim I G\left(\frac{10^{-4}}{2}, \frac{1}{2}\right)
$$

\section{C.2 Simulating the Posterior Distributions}

\section{Time-Varying VAR}

The model is a VAR with drifting coefficients and covariances. This model has become fairly standard in the literature and details on the posterior distributions can be found in a number of papers including Cogley and Sargent and Primiceri. Here, we describe the algorithm briefly.

\section{VAR coefficients $\Phi_{t}$}

The time-varying VAR coefficients are drawn using the methods described by Kim and Nelson.

\section{Elements of $H_{t}$}

Following Cogley and Sargent, the diagonal elements of the VAR covariance matrix are sampled using the methods described by Eric Jacquier, Nicholas G. Polson, and Peter E. Rossi (2004).

\section{Element of $A_{t}$}

Given a draw for $\Phi_{t}$ the VAR model can be written as

$$
A_{t}\left(\tilde{X}_{t}\right)=H^{1 / 2} \omega_{t}
$$


where $\tilde{X}_{t}=X_{t}-a_{t}-\sum_{p=1}^{P} B_{t, p} X_{t-p}=\varepsilon_{t}$ and $\operatorname{Var}\left(H^{1 / 2} \omega_{t}\right)=H_{t}$. This is a system of equations with time-varying coefficients and given a block diagonal form for $\operatorname{Var}\left(\varepsilon_{t}\right)$ the standard methods for state space models described by Kim and Nelson can be applied.

\section{VAR hyperparameters}

Conditional on $X_{t}, \phi_{l, t}, H_{t}$, and $A_{t}$, the innovations to $\Phi_{l, t}, H_{t}$, and $A_{t}$ are observable, which allows us to draw the hyperparameters - the elements of $Q, S$, and the $\sigma_{i}^{2}$-from their respective distributions. 


\section{REFERENCES}

Auer, Raphael, and Andreas M. Fisher. 2010. "The effect of low-wage import competition on U.S. inflationary pressure." Journal of Monetary Economics, 57(4): 491-503.

Auer, Raphael, and Andreas M. Fisher. 2012. "Low-wage import competition, inflationary pressure, and industry dynamics in Europe." European Economic Review. Forthcoming.

Ball, Laurence M. 2006. "Has Globalization Changed Inflation?" NBER Working Paper 12687.

Bernanke, Ben. 2007. "Globalization and Monetary Policy." Speech at the Fourth Economic Summit, Stanford Institute for Economic Policy Research.

Bianchi, Francesco. 2013. "Regime Switches, Agents'Beliefs, and Post-World War II U.S. Macroeconomic Dynamics." Review of Economic Studies, 80(2): 463-490.

Bianchi, Francesco, Haroon Mumtaz, and Paolo Surico. 2009. "The Great Moderation of the Term Structure of U.K. Interest Rates." Journal of Monetary Economics, 56(6): 856-871.

Borio, Claudio, and Andrew Filardo. 2007. "Globalisation and Inflation: New Cross-Country Evidence of the Global Determinants of Domestic Inflation." Bank of International Settlements Working Paper 227.

Calza, Alessandro. 2009. "Globalization, Domestic Inflation and Global Output Gaps: Evidence from the Euro Area." International Finance, 12(3): 301-320.

Clarida, Richard, Jordi Gali, and Mark Gertler. 2002. "A Simple Framework for International Monetary Policy Analysis." Journal of Monetary Economics, 49(5): 879-904.

Ciccarelli, Matteo, and Benoit Mojon. 2010. "Global Inflation." The Review of Economics and Statistics, 92(3): 524-535.

Chen, Natalie, Jean M. Imbs, and Andrew Scott. 2009. "The Dynamics of Trade and Competition." Journal of International Economics, 77(1): 50-62.

Christiano, Lawrence J., Martin Eichenbaum, and Charles L. Evans. 1999. "Monetary Shocks: What Have We Learned and To What End?" In Handbook of Macroeconomics, J. B. Taylor and M. Woodford Eds: $65-148$.

Cogley, Timothy, and Thomas J. Sargent. 2006. "Drifts and volatilities: monetary policies and outcomes in the post WWII U.S." Review of Economic Dynamics, 8(2): 262-302.

Corsetti, Giancarlo, and Paolo Pesenti. 2005. "International Dimensions of Optimal Monetary Policy." Journal of Monetary Economics, 52(2): 281-305.

Davig, Troy, and Taeyoung Doh. 2008. "Monetary Policy Regime Shifts and Inłation Persistence." Research Working Paper RWP 08-16, Federal Reserve Bank of Kansas City. 
Eickmeier, Sandra, and Katharina Pijnenburg. 2013. "The global dimension of inflation - evidence from factor-augmented Phillips curves." Oxford Bulletin of Economics and Statistics, 75(1): 103-122.

Fernandez-Villaverde, Jesus, and Juan F. Rubio-Ramirez. 2008. "How Structural Are Structural Parameters?" in NBER Macroeconomics Annual 200\%, Volume 22: 83-137.

Fisher, Richard W. 2006. "Coping With Globalization's Impact on Monetary Policy." Speech at the Allied Social Science Association Meetings, Boston.

Gali, Jordi, and Tommaso Monacelli. 2008. "Monetary Policy and Exchange Rate Volatility in a Small Open Economy." Review of Economic Studies, 72(3): 707-734.

Gamber, Edward N., and Juann H. Hung. 2001. "Has the Rise in Globalization Reduced U.S. Inflation in the 1990s?" Economic Inquiry, 39(1): 58-73.

Galati, Gabriele, and Melick William. 2006. "The Evolving Inflation Process: An Overview." Bank of International Settlements Working Paper 196.

Justiniano, Alejandro, and Giorgio Primiceri. 2008. "The Time-Varying Volatility of Macroeconomic Fluctuations." American Economic Review, 98(3), 604-41.

Ihrig, Jane, Steven B. Kamin, Deborah Lindner, and Jaime Marquez. 2010. "Some Simple Tests of the Globalization and Inflation Hypothesis." International Finance, 13(3): 343-375.

Jacquier, Eric, Nicholas G. Polson, and Peter E. Rossi. 2004. "Bayesian analysis of stochastic volatility models." Journal of Business and Economic Statistics, 12(4): 371-418.

Kamin, Steven B., Mario Marazzi, and John W. Schindler. 2006. "The Impact of Chinese Exports on Global Import Prices." Review of International Economics, 14(2): 179-201.

Kim, Chang-Jin, and Charles R. Nelson. 1999. "State-Space Models with Regime Switching." MIT Press, Cambridge, Massachusetts.

Leeper, Eric M., Christopher A. Sims, and Tao Zha. 1996. "What Does Monetary Policy Do?" Brookings Papers on Economic Activity, 27(2): 1-78.

Loretan, Mico. 2005. "Indexes of the Foreign Exchange Value of the Dollar." Federal Reserve Bulletin, Winter.

Milani, Fabio. 2010. "Global Slack and Domestic Inflation Rates: A Structural Investigation for the G-7 Countries." Journal of Macroeconomics, 32(4): 968-981.

Mojon, Benoît, and Gert Peersman. 2003. "A VAR Description of the Effects of Monetary Policy in the Individual Countries of the Euro Area." In Monetary Transmission Mechanism in the Euro Area, I. Angeloni, A. K. Kashyap, and B. Mojon Eds., Cambridge University Press: 36-55.

Monacelli, Tommaso. 2005. "Monetary Policy in a Low Pass-Through Environment." Journal of Money, Credit and Banking, 37(6): 1047-1066. 
Mumtaz, Haroon, and Paolo Surico. 2008. "Evolving International Inflation Dynamics: Evidence from a Time-Varying Dynamic Factor Model." Bank of England Working Paper 341.

Peersman, Gert, and Frank Smets. 2003. "The Monetary Transmission Mechanism in the Euro Area: Evidence from VAR Analysis." In Monetary Transmission Mechanism in the Euro Area, I. Angeloni, A. K. Kashyap, and B. Mojon Eds., Cambridge University Press: 36-55.

Primiceri, Giorgio. 2005. "Time Varying Structural Vector Autoregressions and Monetary Policy." Review of Economic Studies, 72(3): 821-852.

Razin, Assaf, and Chi-Wa Yuen. 2002. "'The 'New Keynesian' Phillips Curve: Closed Economy Versus Open Economy." Economics Letters, 75: 1-9.

Rogoff, Kenneth. 2003. "Globalization and Global Disinflation." In Monetary Policy and Uncertainty: Adapting to a Changing Economy, Federal Reserve Bank of Kansas City.

Sbordone, Argia. 2007. "Globalization and Inflation Dynamics: The Impact of Increased Competition." In International Dimensions of Monetary Policy, J. Gali and M. J. Gertler Eds: 547-579.

Schorfheide, Frank. 2005. "Learning and Monetary Policy Shifts." Review of Economic Dynamics, $8(2), 392-419$.

Steinsson, Jón. 2008. "The Dynamic Behavior of the Real Exchange Rate in Sticky-Price Models" American Economic Review, 98(1): 519-533.

Sims, Christopher A., and Tao Zha. 2006. "Were There Regime Switches in U.S. Monetary Policy?" American Economic Review, 96(1): 54-81.

Tootell, Geoffrey M.B. 1998. "Globalization and U.S. Inflation." New England Economic Review, July/August: 21-33.

Wynne, Mark A., and Erasmus K. Kersting. 2007. "Openness and Inflation", Federal Reserve of Dallas Staff Paper 2.

Zaniboni, Nicola. 2008. "Globalization and Phillips Curve." Unpublished manuscript. 


\section{Tables and Figures}

\begin{tabular}{lclclc}
\hline Country & Abbr. & Country & Abbr. & Country & Abbr. \\
\hline \hline United States & $u s$ & Australia & $a u$ & Italy & $i t$ \\
United Kingdom & $u k$ & Japan & $j p$ & Netherlands & $n l$ \\
Canada & $c a$ & South Korea & $k o$ & Spain & es \\
Germany & $g e$ & Austria & oe & Mexico & $m x$ \\
France & $f r$ & Ireland & $i r$ & South Africa & sa \\
Switzerland & $s w$ & Denmark & $d k$ & New Zealand & $n z$ \\
\hline
\end{tabular}

Table 1: Abbreviations used as country codes in Figures and Tables.

\begin{tabular}{lclclc}
\hline Country & Corr. & Country & Corr. & Country & Corr. \\
\hline \hline United States & 0.78 & Australia & 0.36 & Italy & 0.72 \\
United Kingdom & 0.52 & Japan & 0.43 & Netherlands & 0.68 \\
Canada & 0.76 & South Korea & 0.27 & Spain & 0.63 \\
Germany & 0.64 & Austria & 0.58 & Mexico & 0.05 \\
France & 0.70 & Ireland & 0.32 & South Africa & 0.23 \\
Switzerland & 0.62 & Denmark & 0.55 & New Zealand & 0.10 \\
\hline
\end{tabular}

Table 2: Correlations between $y^{d}$ and $y^{f}$.

Notes: Sample contemporaneous correlations of the domestic $\left(y^{d}\right)$ and foreign $\left(y^{f}\right)$ output gap by country.

\begin{tabular}{|c|c|c|c|c|c|c|c|c|c|c|c|c|c|c|c|c|c|c|c|}
\hline & us & $u k$ & $c a$ & $g e$ & $f r$ & $s w$ & $a u$ & $j p$ & $k o$ & $o e$ & $i r$ & $d k$ & $i t$ & $n l$ & $e s$ & $m x$ & $s a$ & $n z$ & all \\
\hline 1980:85 & .15 & .43 & .47 & .48 & .39 & .56 & .26 & .24 & .61 & .86 & .93 & .57 & .48 & .97 & .29 & .17 & .54 & .55 & .50 \\
\hline 1986:90 & .14 & .40 & .46 & .47 & .34 & .53 & .26 & .17 & .56 & .68 & .88 & .49 & .38 & .84 & .27 & .21 & .50 & .46 & .45 \\
\hline 1991:95 & .16 & .39 & .50 & .39 & .34 & .51 & .28 & .15 & .48 & .58 & .95 & .48 & .34 & .77 & .29 & .32 & .41 & .48 & .43 \\
\hline 1996:00 & .18 & .42 & .66 & .44 & .41 & .57 & .32 & .17 & .57 & .62 & 1.20 & .53 & .37 & .85 & .38 & .56 & .49 & .48 & .51 \\
\hline 2001:06 & .19 & .38 & .63 & .57 & .45 & .64 & .32 & .22 & .62 & .71 & 1.07 & .58 & .40 & 1.10 & .40 & .56 & .57 & .48 & .55 \\
\hline$\Delta$ open & .05 & -.05 & .16 & .09 & .05 & .08 & .06 & -.02 & .02 & -.15 & .13 & .01 & -.08 & .13 & .11 & .39 & .04 & -.07 & .05 \\
\hline
\end{tabular}

Table 3: Change in the degree of openness.

Notes: The degree of openness is measured as the sum of imports and exports in ratio to GDP. Averages by five-year periods since 1980 are reported (six years are used at the initial and final part of the sample). The change of openness is defined as the variation in this measure of openness betwen period 1980:85 and period 2001:06. This is reported in the last column ( $\Delta$ open). 


\begin{tabular}{|c|c|c|c|c|c|c|c|c|c|c|c|c|}
\hline & \multicolumn{6}{|c|}{ Equation (11) } & \multicolumn{6}{|c|}{ Equation (12) } \\
\hline & \multicolumn{3}{|c|}{$M E A N$} & \multicolumn{3}{|c|}{$C U M$} & \multicolumn{3}{|c|}{$M E A N$} & \multicolumn{3}{|c|}{$C U M$} \\
\hline & (a) & (b) & (c) & (a) & $(b)$ & (c) & $(a)$ & (b) & (c) & $(a)$ & (b) & $(c)$ \\
\hline open & $\begin{array}{l}-.04 \\
(.07)\end{array}$ & $\begin{array}{l}-.02 \\
(.06)\end{array}$ & $\begin{array}{l}.013 \\
.01)\end{array}$ & $\begin{array}{l}-.68 \\
(1.15)\end{array}$ & $\begin{array}{c}-.32 \\
(1.03)\end{array}$ & $\begin{array}{c}.22 \\
(.18)\end{array}$ & & & & & & \\
\hline$\times D$ & & & & & & & $\begin{array}{r}.05 \\
(.04)\end{array}$ & $\begin{array}{l}.06 \\
(.04)\end{array}$ & $\begin{array}{l}.02 \\
(.014)\end{array}$ & $\begin{array}{l}.76 \\
.(63)\end{array}$ & $(.99)$ & $\begin{array}{l}.35 \\
(.23)\end{array}$ \\
\hline$\times(1-D)$ & & & & & & & $\begin{array}{l}-.13 \\
(.12)\end{array}$ & (.11) & $\begin{array}{c}.008 \\
(.018)\end{array}$ & $\begin{array}{r}-2.01 \\
(1.9)\end{array}$ & $\begin{array}{r}-1.66 \\
(1.85)\end{array}$ & $\begin{array}{l}.13 \\
(.3)\end{array}$ \\
\hline $\operatorname{corr}$ & $\begin{array}{l}.17 \\
(.036)\end{array}$ & $\begin{array}{l}.15 \\
(.04)\end{array}$ & $\begin{array}{c}.09 \\
(.06)\end{array}$ & $\begin{array}{l}\mathbf{2 . 6 9} \\
(.57)\end{array}$ & $\begin{array}{l}\mathbf{2 . 3 5} \\
(.63)\end{array}$ & $\begin{array}{l}1.52 \\
(1.02)\end{array}$ & $\begin{array}{l}.19 \\
(.04)\end{array}$ & $\begin{array}{l}\mathbf{1 7} \\
(.04)\end{array}$ & $\begin{array}{l}.09 \\
(.06)\end{array}$ & $\begin{array}{l}3.02 \\
(.69)\end{array}$ & $\begin{array}{c}\mathbf{2 . 7 2} \\
(.7)\end{array}$ & $\begin{array}{l}1.48 \\
(.95)\end{array}$ \\
\hline trend & & $\begin{array}{l}-.02 \\
(.014)\end{array}$ & $\begin{array}{l}-.07 \\
(.04)\end{array}$ & & $\begin{array}{r}-.33 \\
(.22)\end{array}$ & $\begin{array}{c}-1.12 \\
(.7)\end{array}$ & & $\begin{array}{r}-.016 \\
(.012)\end{array}$ & $\begin{array}{l}-.07 \\
(.04)\end{array}$ & & $\begin{array}{r}-.26 \\
.19)\end{array}$ & $\begin{array}{r}-1.12 \\
(.71)\end{array}$ \\
\hline$m_{t-1}$ & & & $\begin{array}{r}.74 \\
(.015) \\
\end{array}$ & & & $\begin{array}{r}.74 \\
(.016) \\
\end{array}$ & & & $\begin{array}{r}.74 \\
(.017)\end{array}$ & & & $\begin{array}{r}.75 \\
(.017)\end{array}$ \\
\hline$R^{2}$ & .34 & .35 & & .34 & .35 & & .36 & .36 & & .36 & .36 & \\
\hline
\end{tabular}

Table 4: Panel estimates for the $y^{d}$ shock.

Notes: Sample 1980:3 2006:4. Baseline identification ordering $\left(\pi y^{f} y^{d} \tau i\right)$. On the left side, estimates of the model in (11) for the measures, $m_{t}$, derived from the responses of inflation to the $y^{d}$ shock. On the right side, estimates for the model in (12). open is the ratio to GDP of the sum of imports and exports expressed in percentage; corr is (100 times) the correlation of the reduced-form residuals of the $y^{d}$ and $y^{f}$ equations of the VAR; $D$ is a dummy variable and $D=1$ if correlation in Table $2>.5$. The measures used as dependent variables are: $M E A N$, the average response of inflation; $C U M$, the 4-year cumulative response expressed in basis points. Standard fixed effects OLS are used in columns (a) and (b); the Arellano-Bond estimating procedure in columns (c) with $m_{t-2}$ to $m_{t-5}$ as dynamic instruments and $\Delta$ open $_{t}$ as other instruments. Robust White period standard errors are computed. Bold figures indicate significance at the $5 \%$ level.

\begin{tabular}{|c|c|c|c|c|c|c|c|c|c|c|c|c|}
\hline & \multicolumn{6}{|c|}{ Equation (11) } & \multicolumn{6}{|c|}{ Equation (12) } \\
\hline & \multicolumn{3}{|c|}{$M E A N$} & \multicolumn{3}{|c|}{$C U M$} & \multicolumn{3}{|c|}{$M E A N$} & \multicolumn{3}{|c|}{$C U M$} \\
\hline & $(a)$ & $(b)$ & (c) & $(a)$ & $(b)$ & (c) & $(a)$ & $(b)$ & $(c)$ & $(a)$ & $(b)$ & $(c)$ \\
\hline open & $\begin{array}{l}-.1 \\
(.21)\end{array}$ & $\begin{array}{r}-.004 \\
(.19)\end{array}$ & $\begin{array}{c}-.026 \\
(.03)\end{array}$ & $\begin{array}{l}-1.6 \\
(3.36)\end{array}$ & $\begin{array}{l}-.07 \\
(3)\end{array}$ & $\begin{array}{l}-.42 \\
(.48)\end{array}$ & & & & & & \\
\hline$\times D$ & & & & & & & $\begin{array}{l}\mathbf{1 5} \\
(.07)\end{array}$ & $\begin{array}{l}.056 \\
(.045)\end{array}$ & $\begin{array}{l}.09 \\
.05)\end{array}$ & $\underset{(1.1)}{\mathbf{2 . 3 7}}$ & $\underset{(1.2)}{\mathbf{3 . 0 3}}$ & $\begin{array}{l}1.42 \\
(.83)\end{array}$ \\
\hline$\times(1-D)$ & & & & & & & $\begin{array}{l}-.34 \\
(.37)\end{array}$ & $\begin{array}{l}-.1 \\
(.12)\end{array}$ & $\begin{array}{l}-.1 \\
(.02)\end{array}$ & $\begin{array}{r}-5.45 \\
(5.9)\end{array}$ & $\begin{array}{c}-3.46 \\
(5.8)\end{array}$ & $\begin{array}{c}-\mathbf{1 . 5 5} \\
(.35)\end{array}$ \\
\hline corr & $\begin{array}{l}.37 \\
(.07)\end{array}$ & $\begin{array}{r}\mathbf{2 8} \\
(.09)\end{array}$ & $\begin{array}{l}.25 \\
(.1)\end{array}$ & $\begin{array}{l}\mathbf{5 . 9 7} \\
(1.13)\end{array}$ & $\begin{array}{c}\mathbf{4 . 5} \\
(1.48)\end{array}$ & $\begin{array}{c}\mathbf{3 . 9} \\
(1.55)\end{array}$ & $\begin{array}{l}.43 \\
(.09)\end{array}$ & $\begin{array}{l}.17 \\
(.04)\end{array}$ & $\begin{array}{l}\mathbf{2 7} \\
(.09)\end{array}$ & $\begin{array}{r}6.89 \\
(1.49)\end{array}$ & $\begin{array}{l}\mathbf{5 . 4 5} \\
(1.62)\end{array}$ & $\begin{array}{l}\mathbf{4 . 3 7} \\
(1.53)\end{array}$ \\
\hline trend & & $\begin{array}{l}-.09 \\
(.026)\end{array}$ & $\begin{array}{l}-.12 \\
(.08)\end{array}$ & & $\begin{array}{c}-1.44 \\
(.42)\end{array}$ & $\begin{array}{l}-1.96 \\
(1.33)\end{array}$ & & $\begin{array}{r}-.016 \\
(.012)\end{array}$ & $\begin{array}{l}-.11 \\
(.08)\end{array}$ & & $\begin{array}{c}-\mathbf{1 . 2 5} \\
(.29)\end{array}$ & $\begin{array}{l}-1.84 \\
(1.24)\end{array}$ \\
\hline$m_{t-1}$ & & & $\begin{array}{r}.76 \\
(.018) \\
\end{array}$ & & & $\begin{array}{c}.76 \\
(.018) \\
\end{array}$ & & & $\begin{array}{c}.76 \\
(.019) \\
\end{array}$ & & & $\begin{array}{r}.76 \\
(.019) \\
\end{array}$ \\
\hline$R^{2}$ & .36 & .39 & & .36 & .40 & & .39 & .36 & & .39 & .42 & \\
\hline
\end{tabular}

Table 5: Panel estimates for the $y^{f}$ shock.

Notes: See notes for Table 4. The measures, $m_{t}$, are derived from the responses of inflation to the $y^{f}$ shock. 


\begin{tabular}{|c|c|c|c|c|c|c|c|c|c|c|c|c|}
\hline & \multicolumn{6}{|c|}{ Equation (11) } & \multicolumn{6}{|c|}{ Dummy Included } \\
\hline & & $M E A I$ & & & $C U M$ & & & $M E A N$ & & & $C U M$ & \\
\hline & $(a)$ & (b) & (c) & $(a)$ & (b) & (c) & (a) & (b) & (c) & $(a)$ & (b) & (c) \\
\hline open & $\begin{array}{l}-.06 \\
(.15)\end{array}$ & $\begin{array}{l}014 \\
(.13)\end{array}$ & $\begin{array}{l}-.003 \\
(.025)\end{array}$ & $\begin{array}{c}-.92 \\
(2.34)\end{array}$ & $\begin{array}{c}.23 \\
(2.14)\end{array}$ & $\begin{array}{l}-.05 \\
(.4)\end{array}$ & & & & & & \\
\hline$\times D$ & & & & & & & $\begin{array}{l}.14 \\
(.074)\end{array}$ & $\begin{array}{l}. \mathbf{1 7} \\
(.065)\end{array}$ & $\begin{array}{l}.09 \\
(.06)\end{array}$ & $\begin{array}{c}2.24 \\
(1.19)\end{array}$ & $\begin{array}{c}\mathbf{2 . 7 7} \\
(1.05)\end{array}$ & $\begin{array}{l}1.52 \\
(.92)\end{array}$ \\
\hline$\times(1-D)$ & & & & & & & $\begin{array}{l}-.15 \\
(.2)\end{array}$ & $\begin{array}{c}-.067 \\
(.19)\end{array}$ & $\begin{array}{l}-.03 \\
(.02)\end{array}$ & $\begin{array}{c}-2.4 \\
(3.26)\end{array}$ & $\begin{array}{c}-1.07 \\
(3.1)\end{array}$ & $\begin{array}{r}-.55 \\
(.4)\end{array}$ \\
\hline corr & $\begin{array}{r}. \mathbf{2 2} \\
(.05)\end{array}$ & $\begin{array}{l}.15 \\
(.07)\end{array}$ & $\begin{array}{l}\mathbf{1 8} \\
(.08)\end{array}$ & $\begin{array}{l}3.48 \\
(.83)\end{array}$ & $\underset{(1.06)}{\mathbf{2 . 3 7}}$ & $\begin{array}{l}\mathbf{2 . 9 5} \\
(1.3)\end{array}$ & $\begin{array}{l}. \mathbf{2 5} \\
(.06)\end{array}$ & $\begin{array}{l}.18 \\
(.07)\end{array}$ & $\begin{array}{c}.2 \\
(.08)\end{array}$ & $\underset{(1.02)}{\mathbf{3 . 9 9}}$ & $\begin{array}{l}\mathbf{2 . 8 6} \\
(1.12)\end{array}$ & $\begin{array}{l}\mathbf{3 . 2 1} \\
(1.33)\end{array}$ \\
\hline trend & & $\begin{array}{l}-.07 \\
(.018)\end{array}$ & $\begin{array}{l}-.088 \\
(.04)\end{array}$ & & $\begin{array}{c}-\mathbf{1 . 0 8} \\
(1.28)\end{array}$ & $\begin{array}{c}\mathbf{- 1 . 2 4} \\
(.62)\end{array}$ & & $\begin{array}{l}-.06 \\
(.014)\end{array}$ & $\begin{array}{r}-.076 \\
(.037)\end{array}$ & & $\begin{array}{c}-\mathbf{1 . 0 1} \\
(.24)\end{array}$ & $\begin{array}{c}-\mathbf{1 . 2 3} \\
(.59)\end{array}$ \\
\hline$m_{t-1}$ & & & $\begin{array}{l}.77 \\
(.026) \\
\end{array}$ & & & $\begin{array}{l}.77 \\
(.026) \\
\end{array}$ & & & $\begin{array}{r}\mathbf{7 6} \\
(.03) \\
\end{array}$ & & & $\begin{array}{c}.76 \\
(.029) \\
\end{array}$ \\
\hline$R^{2}$ & .49 & .52 & & .49 & .52 & & .50 & .53 & & .50 & .53 & \\
\hline
\end{tabular}

Table 6: Panel estimates for the difference between the effects of the $y^{f}$ and the $y^{d}$ shocks.

Notes: See notes for Table 4. The measures, $m_{t}$, are derived from the difference in the responses of inflation to the $y^{f}$ and the $y^{d}$ shocks.

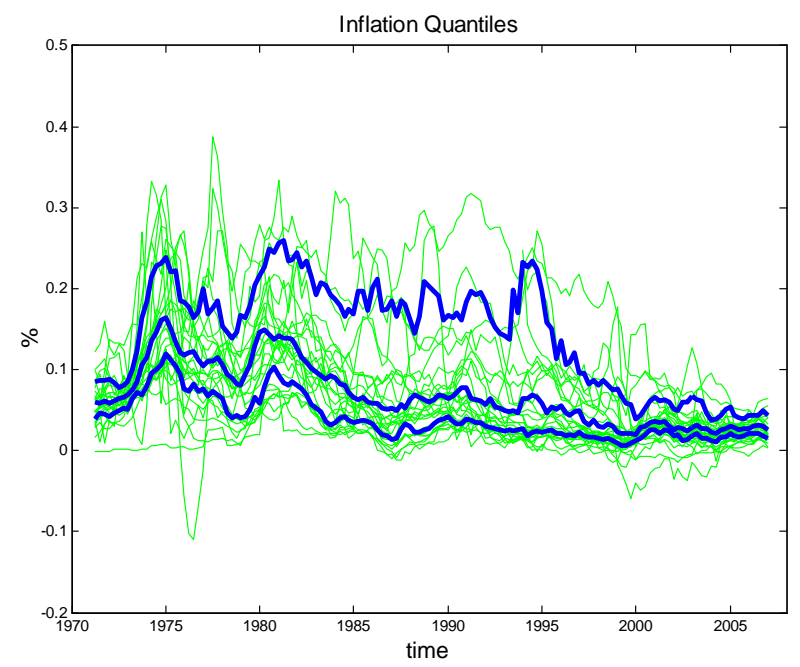

Figure 1: Inflation rates across the world.

Notes: National inflation rates of the countries included in the sample for the construction of the trade-based weights. The thicker and darker lines represent the $5 t h, 50 t h$, and 95th percentiles of the distribution of the inflation rates. Sample period 1971:2006. 


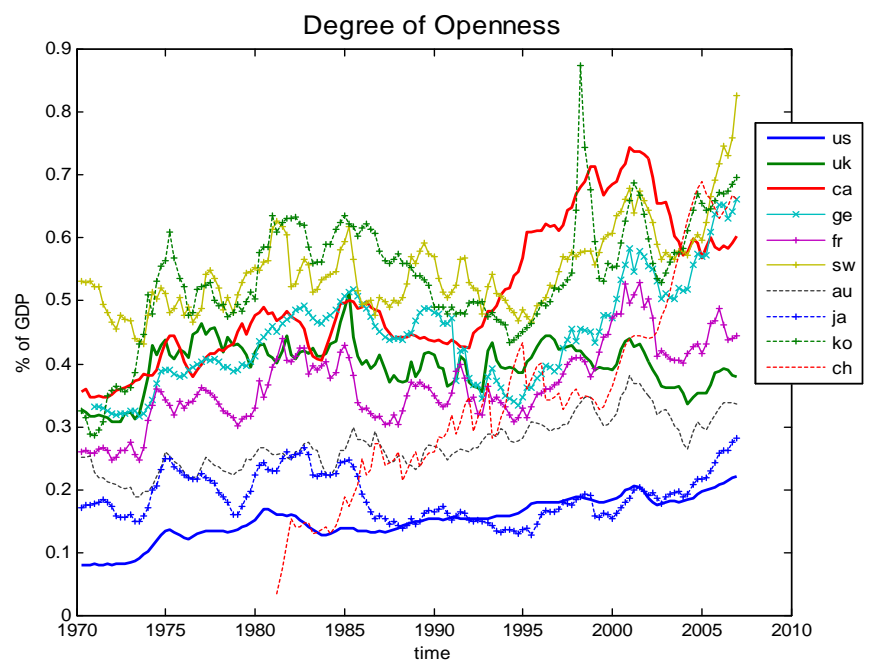

Figure 2: Change in the degree of openness for some countries.

Notes: The degree of openness is measured as the sum of imports and exports in ratio to GDP. The ten countries in this figure are: U.S., U.K., Canada, Germany, France, Switzerland, Australia, Japan, South Korea, and China.

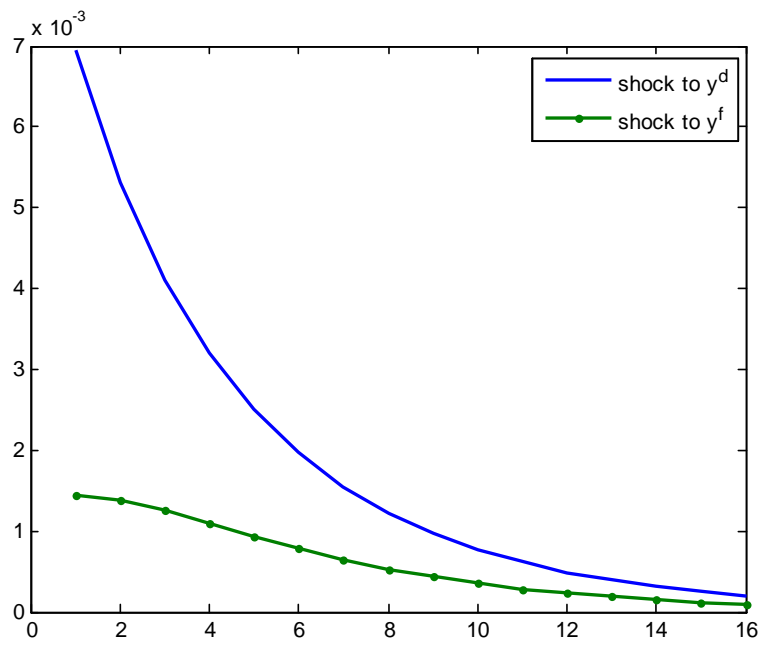

Figure 3: Theoretical response of inflation to domestic and foreign output gap shocks.

Notes: Response of the home country inflation $\pi^{d}$ to a $1 \%$ domestic and foreign output gap shock in a standard New Keynesian open economy DSGE model (see Appendix for more details). 

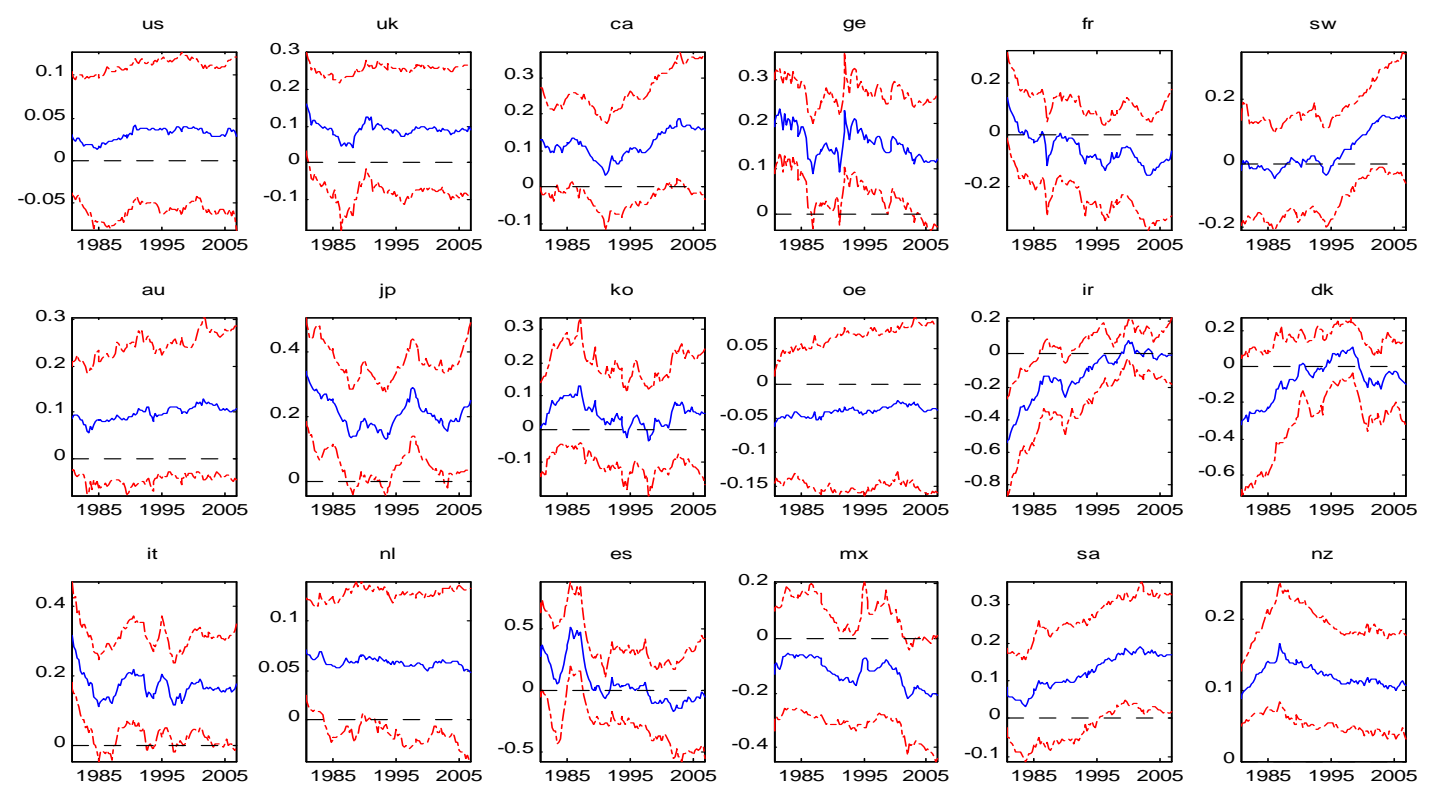

Figure 4: The domestic gap coefficient $\beta$.

Notes: Time variation of the domestic gap coefficient $\beta$ in the $\pi$-equation of the VAR. The bands show the 14th/86th percentile of the posterior distribution of the coefficient.
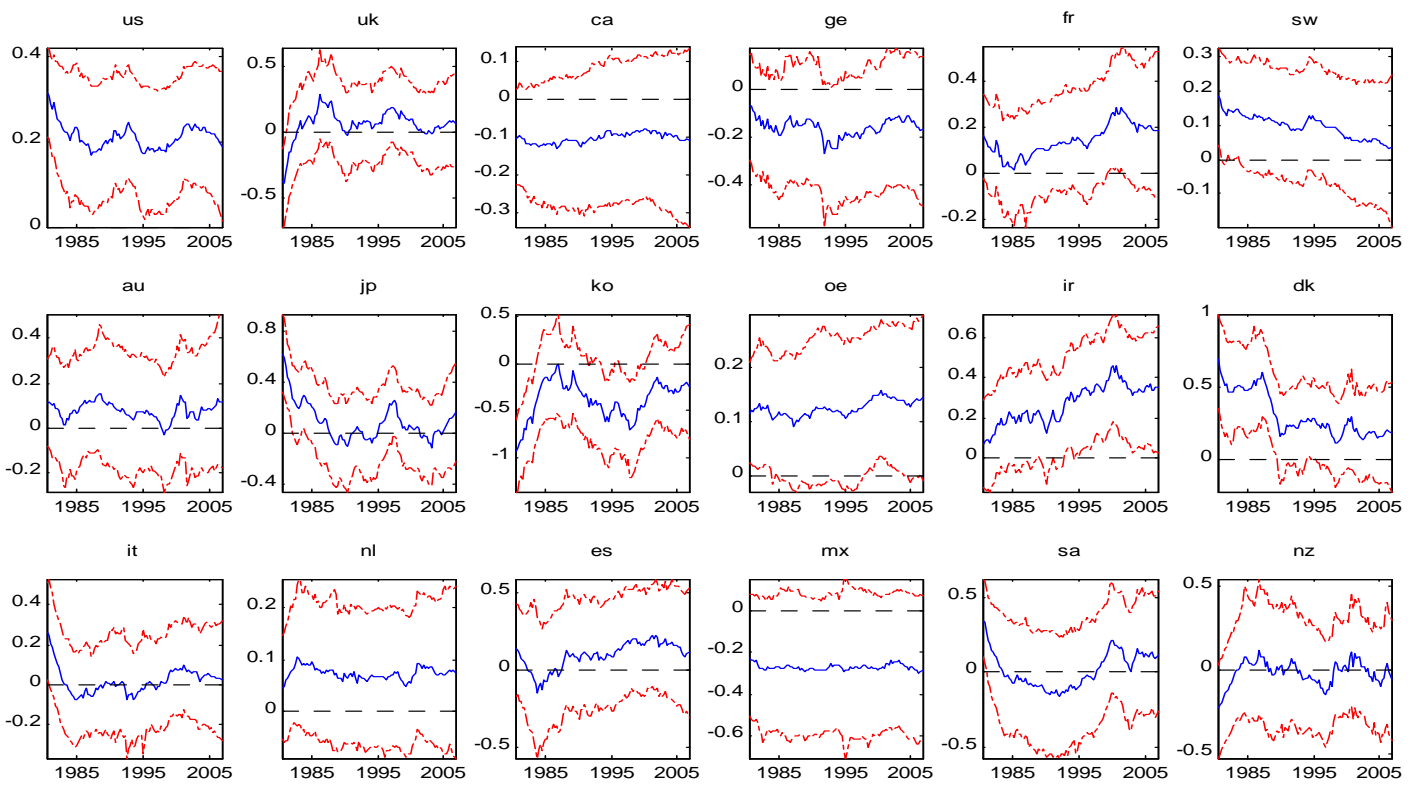

Figure 5: The foreign gap coefficient $\delta$.

Notes: Time variation of the foreign gap coefficient $\delta$ in the $\pi$-equation of the VAR. The bands show the 14th/86th percentile of the posterior distribution of the coefficient. 

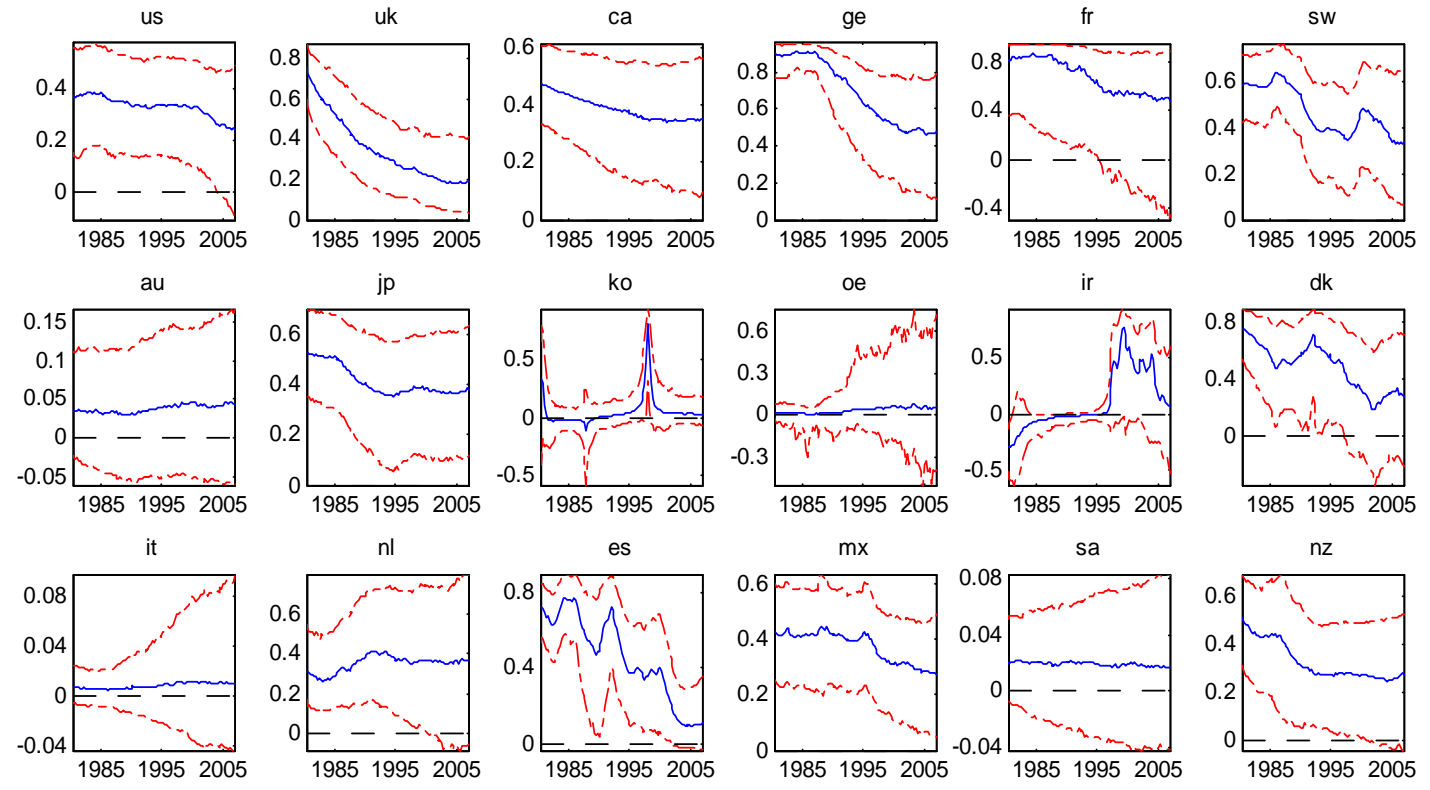

Figure 6: Correlation of the reduced form residuals of the two output gap equations.

Notes: Time variation of the correlation of the reduced form residuals of the $y^{f}$ and $y^{d}$ equations. The bands show the 14th/86th percentile of the posterior distribution of the correlation.
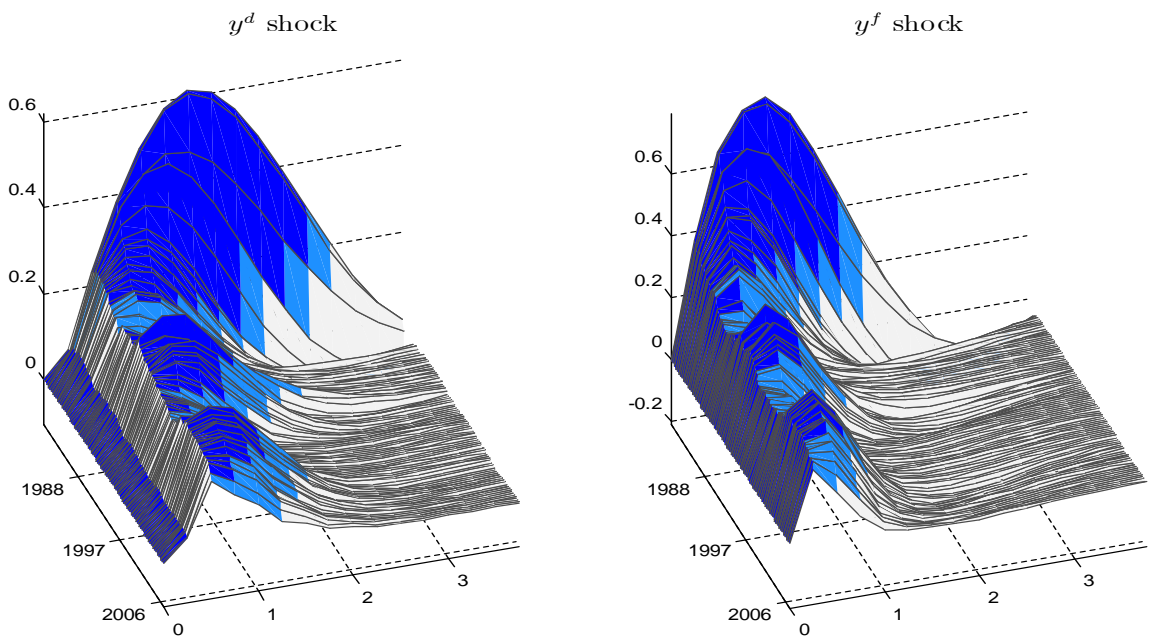

Figure 7: Responses of $\pi$ to a unit shock to $y^{d}$ and $y^{f}$ for U.S.

Notes: Responses of inflation $\pi$ to domestic and foreign output gap shocks for U.S. for each quarter in the sample 1980:3 to 2006:4. The baseline identification ordering $\left(\pi y^{f} y^{d} \tau i\right)$ is adopted. The light blue shades indicate significance at the 14th/86th percentiles of the posterior distribution of the response. Darker blue shades indicate significance at the 5 th $/ 95$ th percentiles. Years from the shock on the $x$-axis. 

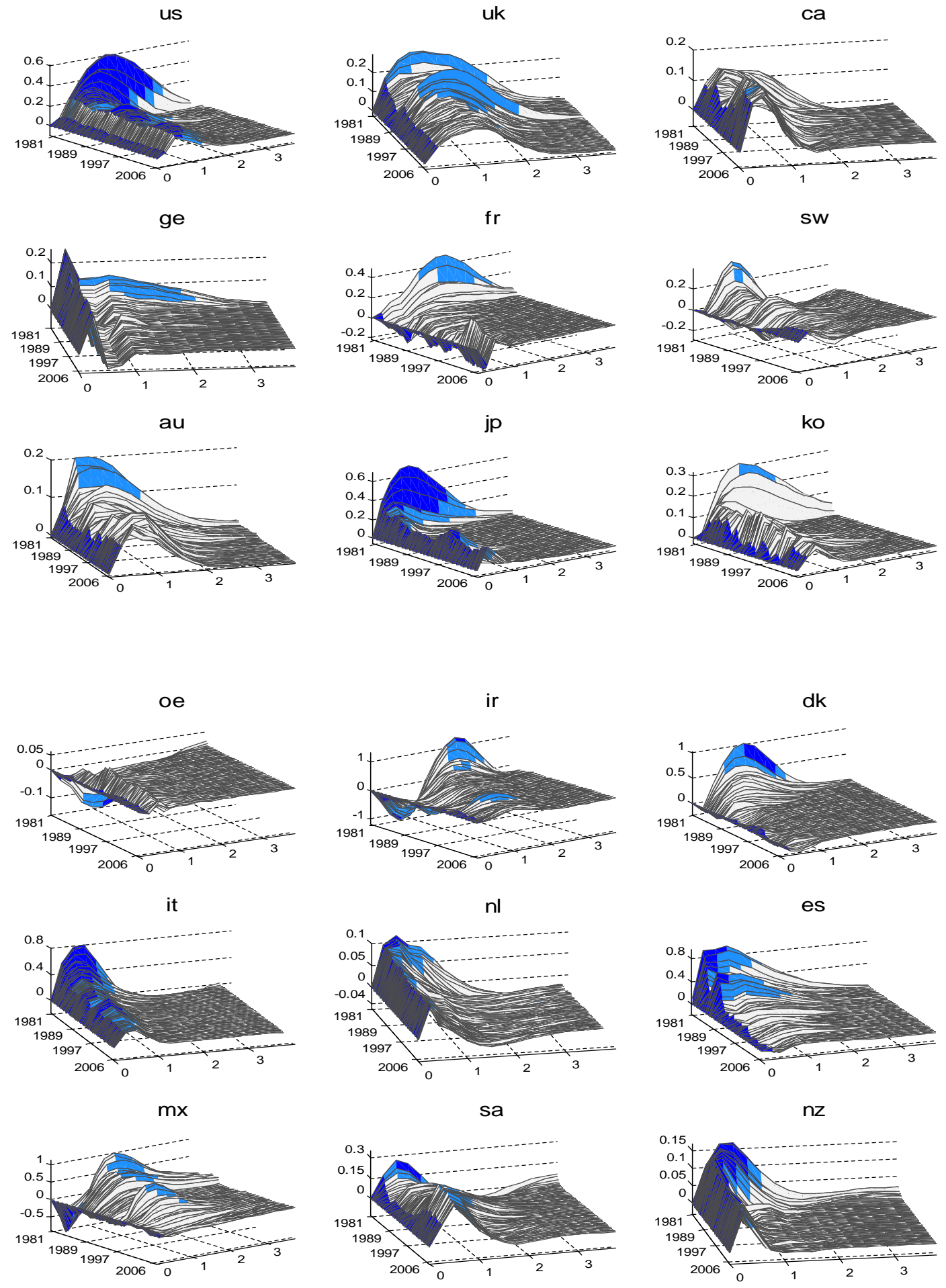

Figure 8: The response of inflation $\pi$ to a unit shock to the domestic output gap $y^{d}$.

Notes: Responses of $\pi$ to the domestic output gap shocks for each quarter in the sample 1980:3 to 2006:4. The baseline identification ordering $\left(\pi y^{f} y^{d} \tau i\right)$ is adopted. The light blue shades indicate significance at the 14 th/86th percentiles of the posterior distribution of the response. Darker blue shades indicate significance at the 5 th/95th percentiles. Years from the shock on the $x$-axis. 

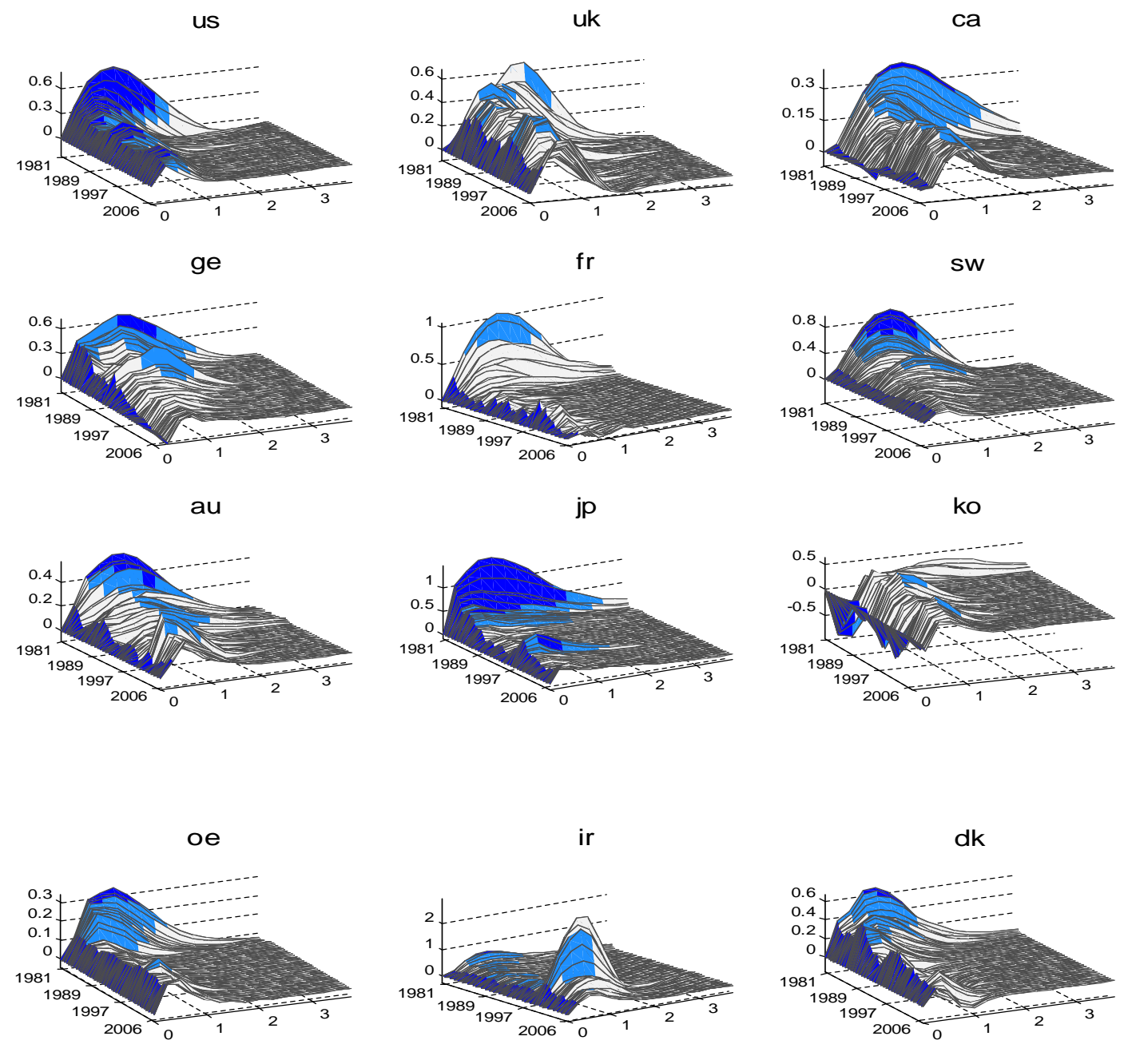

it

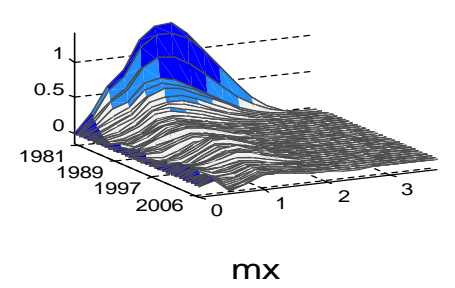

$\mathrm{nl}$
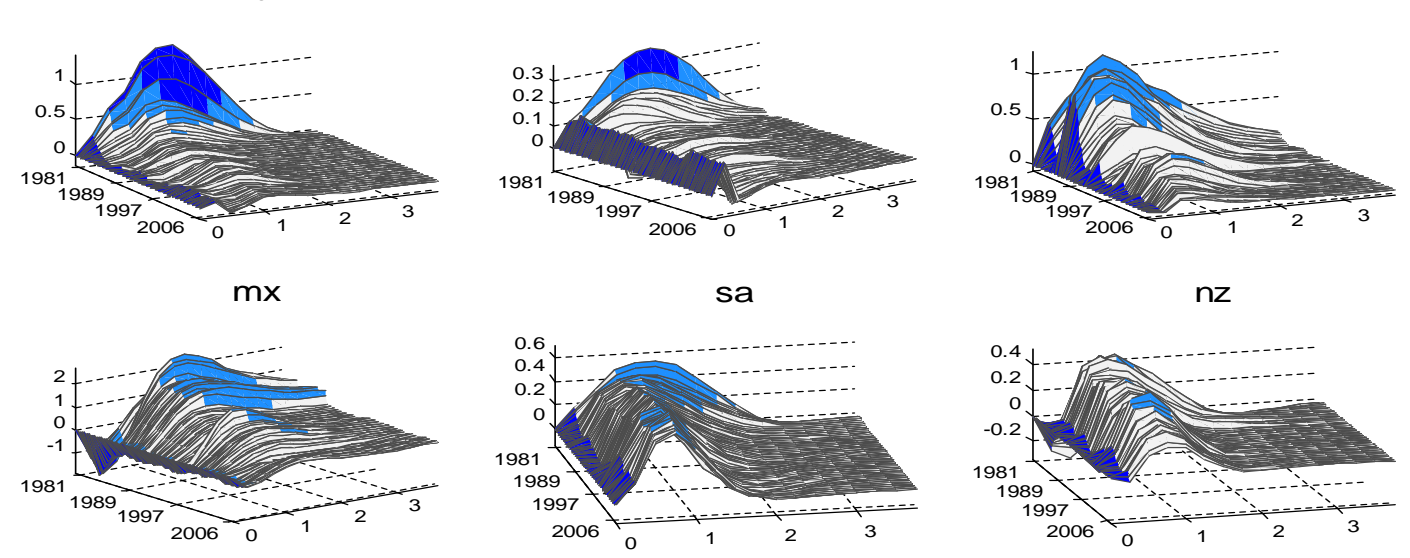

Figure 9: The response of inflation $\pi$ to a unit shock to the foreign output gap $y^{f}$.

Notes: Responses of $\pi$ to foreign output gap shocks for each quarter in the sample 1980:3 to 2006:4. The baseline identification ordering $\left(\pi y^{f} y^{d} \tau i\right)$ is adopted. The light blue shades indicate significance at the 14th/86th percentiles of the posterior distribution of the response. Darker blue shades indicate significance at the 5 th/95th percentiles 
us

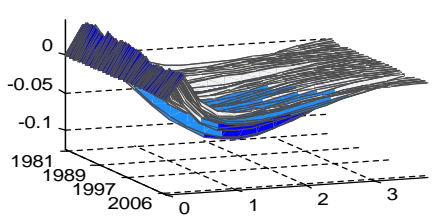

ge

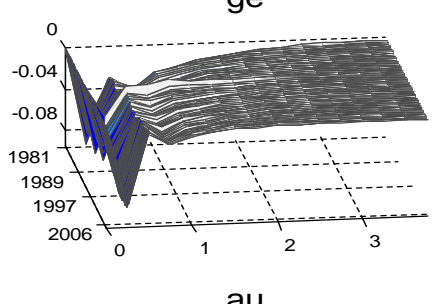

au

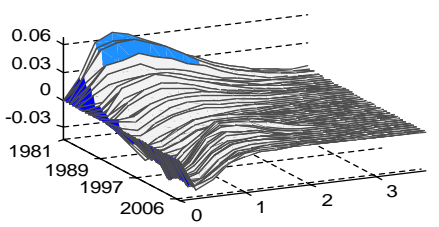

oe

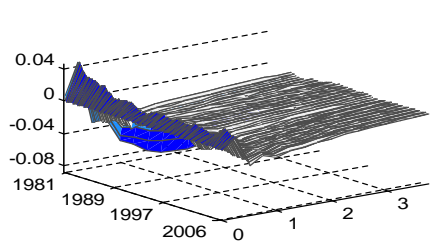

it

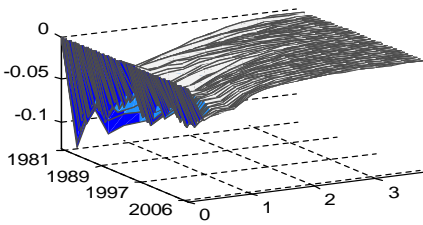

$\mathrm{mx}$

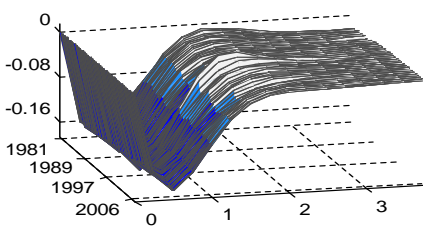

uk

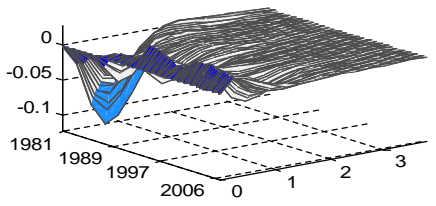

fr

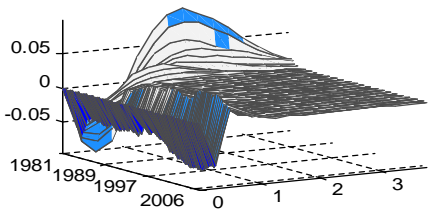

jp

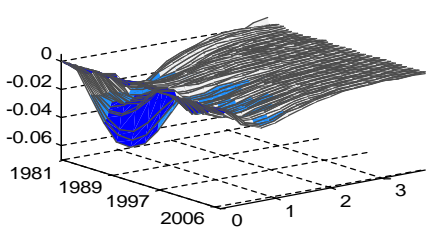

ir

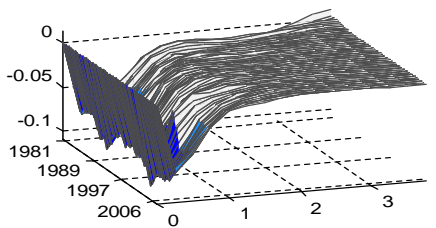

nl

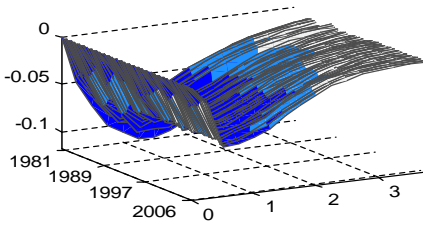

sa

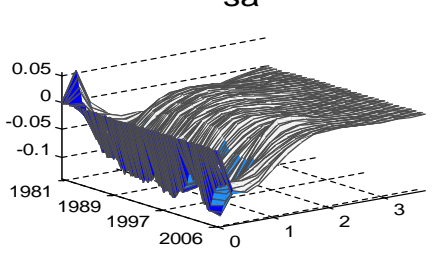

ca

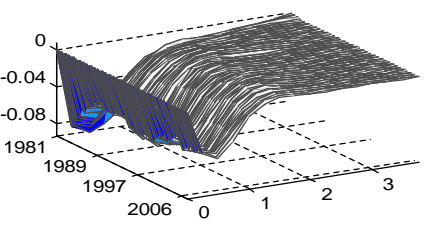

SW

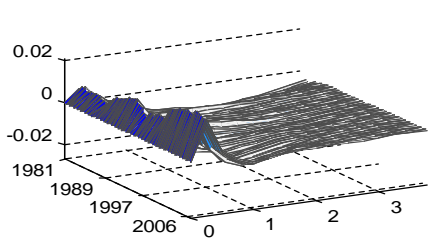

ko

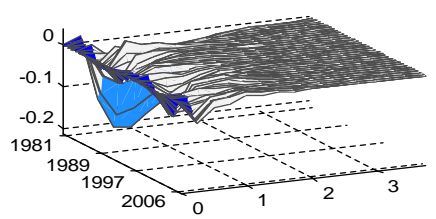

dk

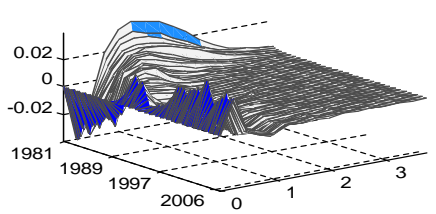

es

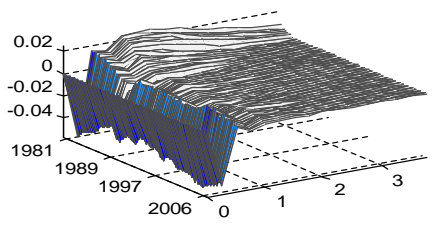

nz

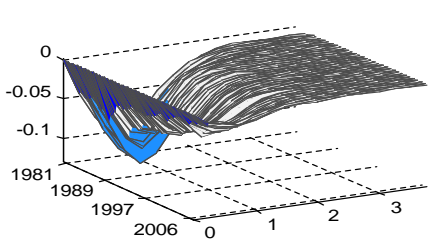

Figure 10: The response of domestic inflation $\pi$ to a unit shock to the real exchange rate $\tau$.

Notes: Responses of $\pi$ to the real exchange rate shocks for each quarter in the sample 1980:3 to 2006:4. The baseline identification ordering $\left(\pi y^{f} y^{d} \tau i\right)$ is adopted. The light blue shades indicate significance at the 14th/86th percentiles of the posterior distribution of the response. Darker blue shades indicate significance at the 5th/95th percentiles. Years from the shock on the $x$-axis. 


\section{Complementary Material (not for publication)}

\begin{tabular}{|c|c|c|c|c|c|c|c|c|c|c|c|c|}
\hline & \multicolumn{6}{|c|}{ Equation (11) } & \multicolumn{6}{|c|}{ Equation (12) } \\
\hline & \multicolumn{3}{|c|}{$M E A N$} & \multicolumn{3}{|c|}{$C U M$} & \multicolumn{3}{|c|}{$M E A N$} & \multicolumn{3}{|c|}{$C U M$} \\
\hline & $(a)$ & $(b)$ & $(c)$ & (a) & (b) & (c) & $(a)$ & $(b)$ & $(c)$ & (a) & (b) & (c) \\
\hline open & $\begin{array}{l}-.1 \\
(.07)\end{array}$ & $\begin{array}{c}-.02 \\
(.06)\end{array}$ & $\begin{array}{l}.014 \\
(.01)\end{array}$ & $\begin{array}{c}-1.58 \\
(1.1)\end{array}$ & $\begin{array}{c}-1.53 \\
(.99)\end{array}$ & $\begin{array}{c}1 \\
(.56)\end{array}$ & & & & & & \\
\hline$\times D$ & & & & & & & $\begin{array}{l}-.07 \\
(.04)\end{array}$ & $\begin{array}{l}-.04 \\
(.05)\end{array}$ & $\begin{array}{c}.02 \\
(.02)\end{array}$ & $\begin{array}{c}-1.17 \\
(.07)\end{array}$ & $\begin{array}{r}-.66 \\
(.8)\end{array}$ & $\begin{array}{l}.35 \\
(.33)\end{array}$ \\
\hline$\times(1-D)$ & & & & & & & $\begin{array}{l}-.12 \\
(.14)\end{array}$ & $\begin{array}{r}-.03 \\
(.16)\end{array}$ & $\begin{array}{c}.1 \\
(.046)\end{array}$ & $\begin{array}{r}-1.99 \\
(2.24)\end{array}$ & $\begin{array}{l}-.47 \\
(2.5)\end{array}$ & $\begin{array}{l}1.54 \\
(.74)\end{array}$ \\
\hline $\operatorname{corr}$ & $\begin{array}{l}.03 \\
(.06)\end{array}$ & $\begin{array}{r}.15 \\
(.04)\end{array}$ & $\begin{array}{l}.09 \\
(.07)\end{array}$ & (i.02) & $\begin{array}{l}-.19 \\
(1.12)\end{array}$ & $\begin{array}{c}-1.28 \\
(1.1)\end{array}$ & $\begin{array}{l}.03 \\
(.07)\end{array}$ & $\begin{array}{r}-.03 \\
(.07)\end{array}$ & $\begin{array}{l}-.09 \\
.07)\end{array}$ & $\begin{array}{l}.57 \\
(1.2)\end{array}$ & $\begin{array}{r}-.53 \\
(1.05)\end{array}$ & $\begin{array}{r}-1.43 \\
(1.16)\end{array}$ \\
\hline trend & & $\begin{array}{l}-.02 \\
(.014)\end{array}$ & $\begin{array}{l}-.07 \\
(.04)\end{array}$ & & $\begin{array}{r}-.75 \\
(.25)\end{array}$ & $\begin{array}{c}-1.66 \\
(.9)\end{array}$ & & $\begin{array}{r}-.06 \\
(.02)\end{array}$ & $\begin{array}{l}-.1 \\
(.06)\end{array}$ & & $\begin{array}{r}-.96 \\
(.33)\end{array}$ & $\begin{array}{c}-1.67 \\
(.95)\end{array}$ \\
\hline$m_{t-1}$ & & & $\begin{array}{c}.74 \\
(.016)\end{array}$ & & & $\begin{array}{r}85 \\
(.04)\end{array}$ & & & $\begin{array}{l}85 \\
(.04)\end{array}$ & & & $\begin{array}{l}-.85 \\
(.04)\end{array}$ \\
\hline$R^{2}$ & .34 & .35 & & .34 & .51 & & .34 & .37 & & .34 & .37 & \\
\hline
\end{tabular}

Table E1: Panel estimates for the $y^{d}$ shock.

Notes: Sample 1980:3 2006:4. Identification ordering $\left(y^{f} y^{d} \pi \tau i\right)$. On the left side, estimates of the model in (11) for the measures, $m_{t}$, derived from the responses of inflation to the $y^{d}$ shock. On the right side, estimates for the model in (12). open is the ratio to GDP of the sum of imports and exports expressed in percentage; corr is (100 times) the correlation of the reduced-form residuals of the $y^{d}$ and $y^{f}$ equations of the VAR; $D$ is a dummy variable and $D=1$ if correlation in Table $2>.5$. The measures used as dependent variables are: $M E A N$, the average response of inflation; $C U M$, the 4-year cumulative response expressed in basis points. Standard fixed effects OLS are used in columns (a) and (b); the Arellano-Bond estimating procedure in columns (c) with $m_{t-2}$ to $m_{t-5}$ as dynamic instruments and open $_{t}$ as other instruments. Robust White period standard errors are computed. Bold figures indicate significance at the $5 \%$ level.

\begin{tabular}{|c|c|c|c|c|c|c|c|c|c|c|c|c|}
\hline & \multicolumn{6}{|c|}{ Equation (11) } & \multicolumn{6}{|c|}{ Equation (12) } \\
\hline & \multicolumn{3}{|c|}{$M E A N$} & \multicolumn{3}{|c|}{$C U M$} & \multicolumn{3}{|c|}{$M E A N$} & \multicolumn{3}{|c|}{$C U M$} \\
\hline & $(a)$ & $(b)$ & $(c)$ & $(a)$ & $(b)$ & (c) & $(a)$ & (b) & $(c)$ & $(a)$ & (b) & (c) \\
\hline "open & $\begin{array}{l}.14 \\
(.09)\end{array}$ & $\begin{array}{l}\mathbf{1 9} \\
(.08)\end{array}$ & $\begin{array}{l}.05 \\
(.046)\end{array}$ & $\begin{array}{l}2.32 \\
(1.48)\end{array}$ & $\begin{array}{l}\mathbf{3 . 1 2} \\
(1.25)\end{array}$ & $\begin{array}{l}-.83 \\
(.74)\end{array}$ & & & & & & \\
\hline$\times D$ & & & & & & & $\begin{array}{l}.16 \\
(.09)\end{array}$ & $\begin{array}{l}.18 \\
. .09)\end{array}$ & $\begin{array}{l}.11 \\
(.07)\end{array}$ & $\begin{array}{l}2.58 \\
(1.5)\end{array}$ & $\underset{(1.48)}{\mathbf{2 . 9 8}}$ & $\begin{array}{c}1.75 \\
(1.11)\end{array}$ \\
\hline$\times(1-D)$ & & & & & & & $\begin{array}{l}.13 \\
(.14)\end{array}$ & $\begin{array}{l}.20 \\
. .11)\end{array}$ & $\begin{array}{l}-.14 \\
(.05)\end{array}$ & $\begin{array}{l}2.07 \\
(2.2)\end{array}$ & $\begin{array}{c}3.28 \\
(1.84)\end{array}$ & $\begin{array}{l}-\mathbf{2 . 3} \\
(.79)\end{array}$ \\
\hline corr & $\begin{array}{l}.4 \\
(.14)\end{array}$ & $\begin{array}{l}.36 \\
(.19)\end{array}$ & $\begin{array}{l}.13 \\
.15)\end{array}$ & $\underset{(2.3)}{\mathbf{6 . 5 1}}$ & $\begin{array}{l}5.73 \\
(3.09)\end{array}$ & $\begin{array}{l}2.08 \\
(2.5)\end{array}$ & $\begin{array}{l}.41 \\
(.14)\end{array}$ & $\begin{array}{l}.35 \\
(.19)\end{array}$ & $\begin{array}{l}.16 \\
(.15)\end{array}$ & $\begin{array}{l}\mathbf{6 . 5 7} \\
(2.3)\end{array}$ & $\begin{array}{l}5.69 \\
(3.1)\end{array}$ & $\begin{array}{l}2.63 \\
(2.44)\end{array}$ \\
\hline trend & & $\begin{array}{l}-.047 \\
(.05)\end{array}$ & $\begin{array}{l}-.1 \\
(.06)\end{array}$ & & $\begin{array}{l}-.75 \\
(.84)\end{array}$ & $\begin{array}{l}-\mathbf{1 . 5 7} \\
(1.03)\end{array}$ & & $\begin{array}{l}-.047 \\
(.05)\end{array}$ & $\begin{array}{l}-.09 \\
(.06)\end{array}$ & & $\begin{array}{l}-.76 \\
(.83)\end{array}$ & $\begin{array}{c}-1.48 \\
(.97)\end{array}$ \\
\hline$m_{t-1}$ & & & $\begin{array}{c}86 \\
.01)\end{array}$ & & & $\begin{array}{l}.86 \\
(.01)\end{array}$ & & & $\begin{array}{l}.86 \\
(.01)\end{array}$ & & & $\begin{array}{l}.86 \\
(.01)\end{array}$ \\
\hline$R^{2}$ & .29 & .30 & & .29 & .30 & & .29 & .30 & & .29 & .30 & \\
\hline
\end{tabular}

Table E2: Panel estimates for the $y^{f}$ shock.

Notes: See notes for Table E1. The measures, $m_{t}$, are derived from the responses of inflation to the $y^{f}$ shock. 


\begin{tabular}{|c|c|c|c|c|c|c|c|c|c|c|c|c|}
\hline & \multicolumn{6}{|c|}{ Equation (11) } & \multicolumn{6}{|c|}{ Equation (12) } \\
\hline & & $\overline{M E A \Lambda}$ & & & $\overline{C U M}$ & & & $\overline{M E A I}$ & & & $C U M$ & \\
\hline & $(a)$ & (b) & (c) & (a) & (b) & (c) & $(a)$ & (b) & (c) & (a) & (b) & (c) \\
\hline open & $\begin{array}{l}.24 \\
(.06)\end{array}$ & $\begin{array}{c}\mathbf{2 3} \\
(.07)\end{array}$ & $\begin{array}{l}-.11 \\
(.08)\end{array}$ & $\begin{array}{c}\mathbf{3 . 8 6} \\
(.97)\end{array}$ & $\begin{array}{c}\mathbf{3 . 6 3} \\
(1.07)\end{array}$ & $\begin{array}{l}-1.86 \\
(1.23)\end{array}$ & & & & & & \\
\hline$\times D$ & & & & & & & $\underset{(.1)}{.24}$ & $\begin{array}{l}.23 \\
(.1)\end{array}$ & $\begin{array}{l}.08 \\
(.06)\end{array}$ & $\underset{(1.72)}{3.81}$ & $\begin{array}{c}\mathbf{3 . 6 9} \\
(1.57)\end{array}$ & $\begin{array}{l}1.31 \\
(1.02)\end{array}$ \\
\hline$\times(1-D)$ & & & & & & & $\begin{array}{c}.24 \\
(.05)\end{array}$ & $\begin{array}{l}.22 \\
(.1)\end{array}$ & $\begin{array}{l}-.24 \\
(.07)\end{array}$ & $\begin{array}{l}\mathbf{3 . 9} \\
(.87)\end{array}$ & $\begin{array}{c}\mathbf{3 . 5 6} \\
(1.65)\end{array}$ & $\begin{array}{c}-3.86 \\
(1.08)\end{array}$ \\
\hline corr & $\begin{array}{c}.38 \\
(.16)\end{array}$ & 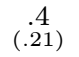 & $\begin{array}{c}.23 \\
(.19)\end{array}$ & $\begin{array}{c}\mathbf{6 . 1 5} \\
(2.62)\end{array}$ & $\begin{array}{l}6.37 \\
(3.4)\end{array}$ & $\begin{array}{c}3.72 \\
(3.12)\end{array}$ & $\begin{array}{c}.38 \\
(.17)\end{array}$ & $\begin{array}{l}.4 \\
(.23)\end{array}$ & $\begin{array}{r}.29 \\
(.2)\end{array}$ & $\begin{array}{l}\mathbf{6 . 1 4} \\
(2.73)\end{array}$ & $\begin{array}{c}\mathbf{6 . 3 9} \\
(3.65)\end{array}$ & $\begin{array}{l}4.7 \\
(3.15)\end{array}$ \\
\hline trend & & $\begin{array}{r}.013 \\
.06)\end{array}$ & $\begin{array}{l}-.06 \\
(.06)\end{array}$ & & $\begin{array}{l}0.21 \\
(1.03)\end{array}$ & $\begin{array}{l}-1.03 \\
(1.02)\end{array}$ & & $\begin{array}{l}.013 \\
(.07)\end{array}$ & $\begin{array}{l}-.045 \\
(.05)\end{array}$ & & $\begin{array}{c}22 \\
(1.07)\end{array}$ & $\begin{array}{l}-.73 \\
(.87)\end{array}$ \\
\hline$m_{t-1}$ & & & $\begin{array}{r}.89 \\
(.01)\end{array}$ & & & $\begin{array}{r}\mathbf{8 9} \\
(.01) \\
\end{array}$ & & & $\begin{array}{l}.88 \\
(.01)\end{array}$ & & & $\begin{array}{l}.88 \\
(.01)\end{array}$ \\
\hline$R^{2}$ & .33 & .33 & & .33 & .33 & & .33 & .33 & & .33 & .33 & \\
\hline
\end{tabular}

Table E3: Panel estimates for the difference between the effects of the $y^{f}$ and the $y^{d}$ shocks.

Notes: See notes for Table E1. The measures, $m_{t}$, are derived from the difference in the responses of inflation to the $y^{f}$ and the $y^{d}$ shocks.
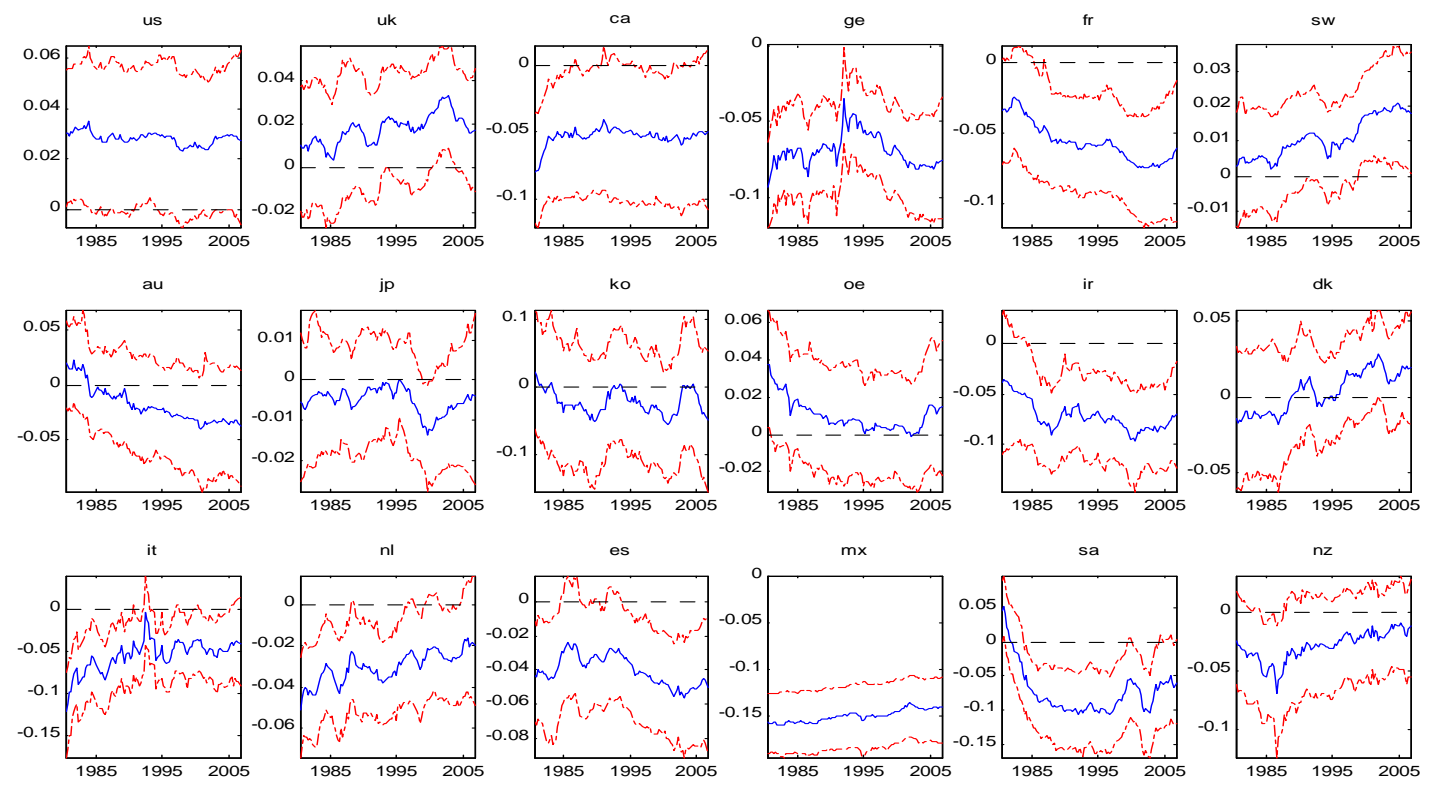

Figure E1: The real exchange rate coefficient $\gamma$.

Notes: Time variation of the real exchange rate coefficient $\gamma$ in the $\pi$-equation of the VAR. The bands show the 14 th/86th percentile of the posterior distribution of the coefficient. 


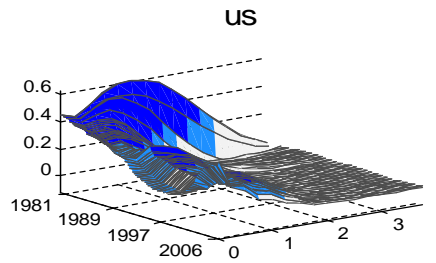

ge

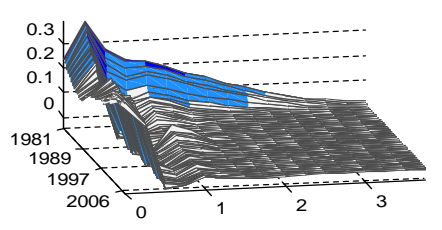

$\mathrm{au}$
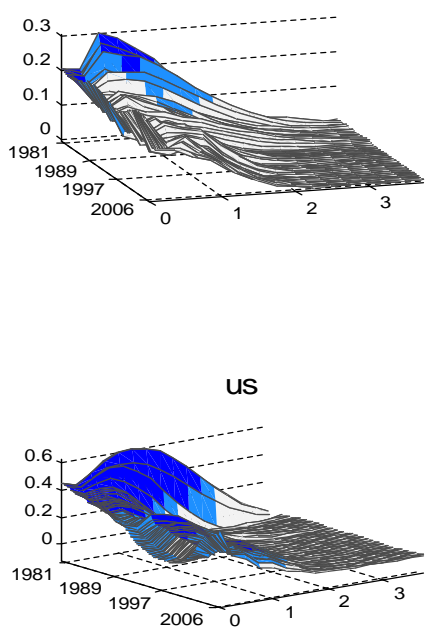

ge

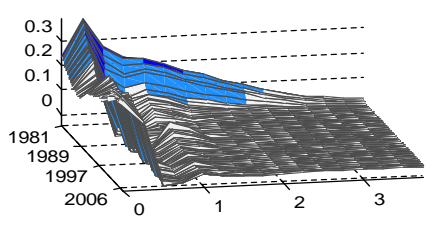

$\mathrm{au}$

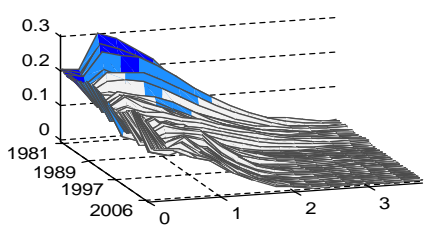

uk

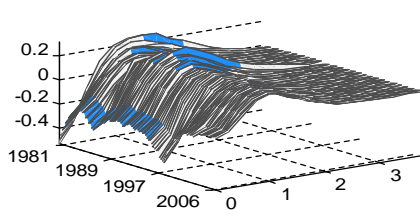

$\mathrm{fr}$

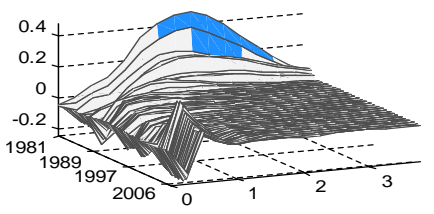

jp

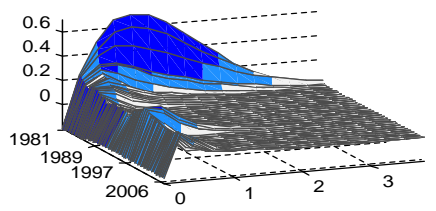

uk

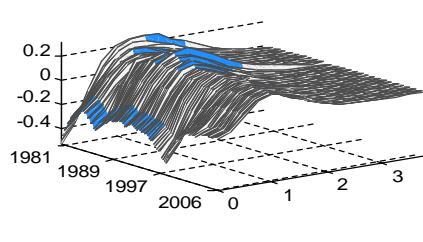

$\mathrm{fr}$

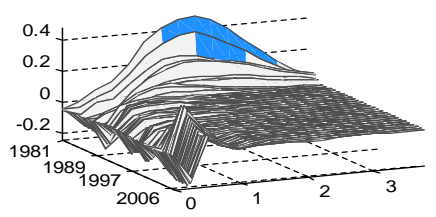

jp

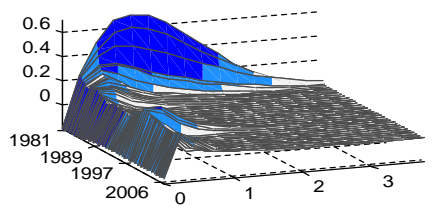

ca

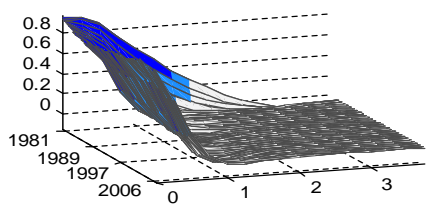

sw

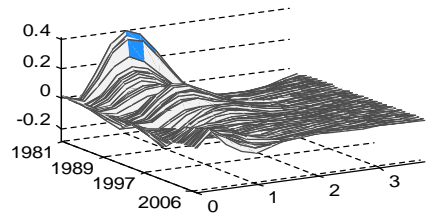

ko

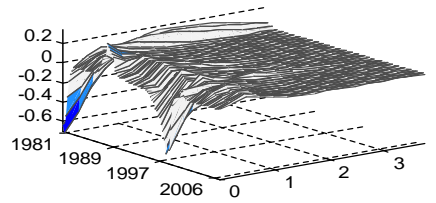

ca

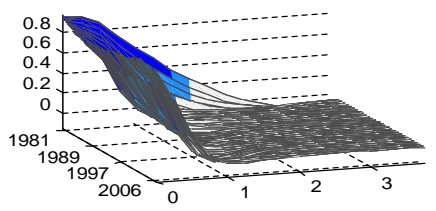

SW

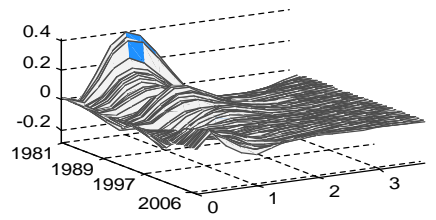

ko

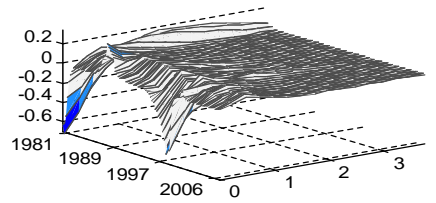

Figure E2: The response of inflation $\pi$ to a unit shock to the domestic output gap $y^{d}$. Second identification scheme.

Notes: Repsonses of $\pi$ to the domestic output gap shocks for each quarter in the sample 1980:3 to 2006:4. The alternative identification ordering $\left(y^{f} y^{d} \pi \tau i\right)$ is adopted. The light blue shades indicate significance at the 14th/86th percentiles of the posterior distribution of the response. Darker blue shades indicate significance at the 5th/95th percentiles. Years from the shock on the $x$-axis. 

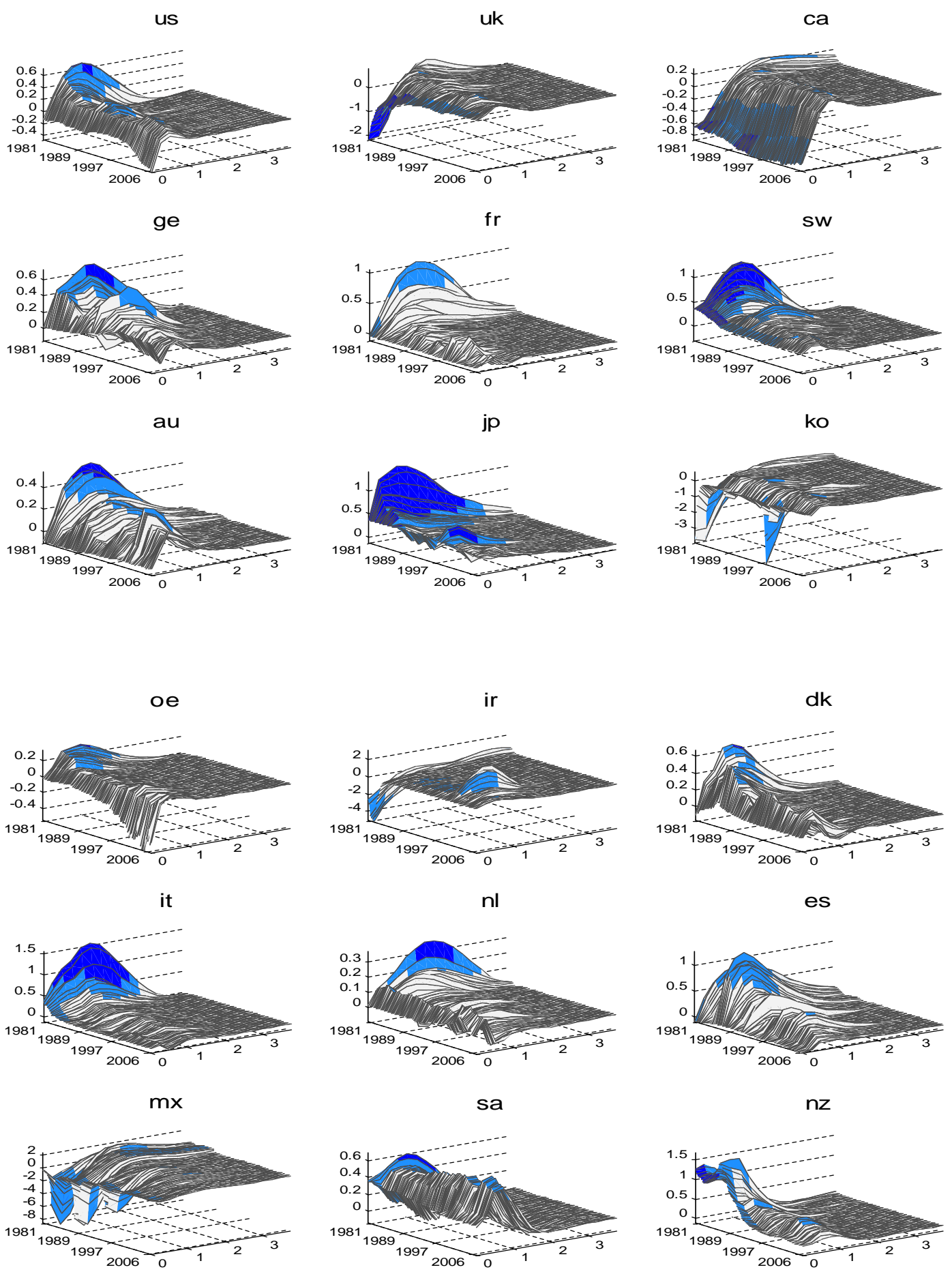

Figure E3: The response of inflation $\pi$ to a unit shock to the foreign output gap $y^{f}$. Second identification scheme.

Notes: Responses of $\pi$ to the foreign output gap shocks for each quarter in the sample 1980:3 to 2006:4. The alternative identification ordering $\left(y^{f} y^{d} \pi \tau i\right)$ is adopted. The light blue shades indicate significance at the 14th/86th percentiles of the posterior distribution of the response. Darker blue shades indicate significance at the 5th/95th percentiles. Years from the shock on the $x$-axis. 